\title{
Plate tectonics drive deep biosphere microbial community structure
}

Katherine M. Fullerton ${ }^{1}$, Matthew O. Schrenk ${ }^{2}$, Mustafa Yücel ${ }^{3}$, Elena Manini ${ }^{4}$, Marco Basili ${ }^{1,4}$, Timothy J. Rogers ${ }^{1}$, Daniele Fattorini ${ }^{5,6}$, Marta Di Carlo ${ }^{5}$, Giuseppe d'Errico ${ }^{5,6}$, Francesco Regoli ${ }^{5,6}$, Mayuko Nakagawa ${ }^{7}$, Costantino Vetriani $^{8,9}$, Francesco Smedile ${ }^{4,9}$, Carlos Ramírez ${ }^{10}$, Heather Miller ${ }^{2}$, Shaunna M. Morrison ${ }^{11}$, Joy Buongiorno ${ }^{11}$, Gerdhard L. Jessen $^{12}$, María Martínez ${ }^{13}$, J. Maarten de Moor ${ }^{13,14}$, Peter H. Barry ${ }^{15}$, Donato Giovannelli ${ }^{4,7,9,16^{*}}$, and Karen G. Lloyd ${ }^{1 *}$

\section{Affiliations:}

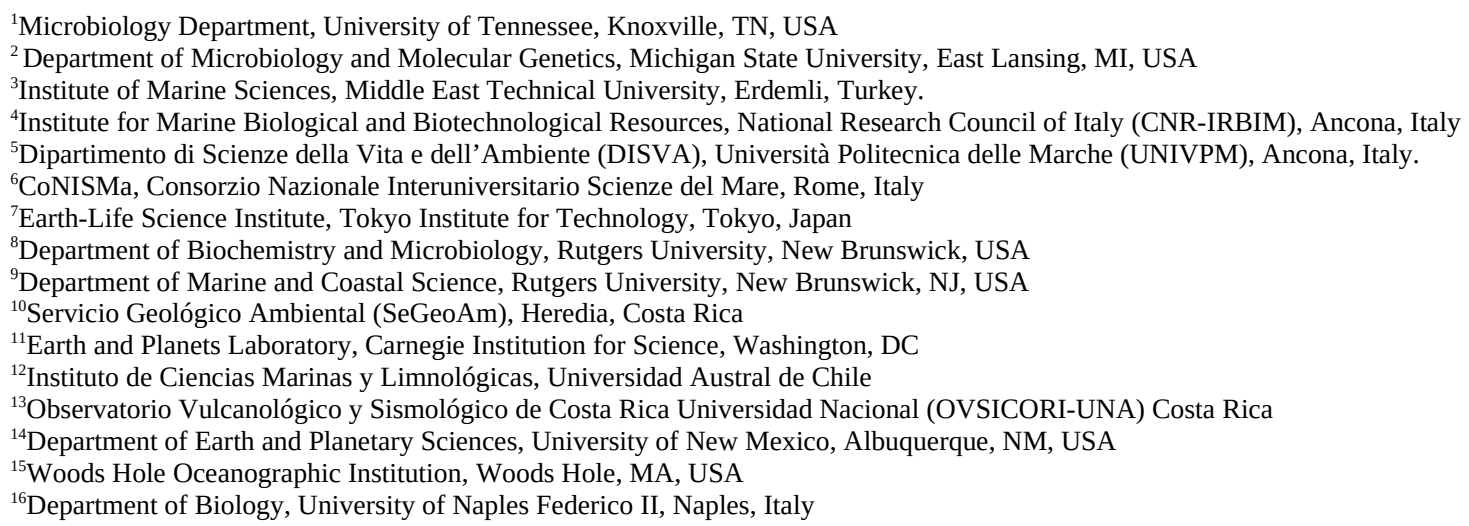

*Correspondence to: donato.giovannelli@unina.it and klloyd@utk.edu

\section{This is a non-peer reviewed preprint submitted to EarthArXiv}

Summary paragraph: The deep subsurface is one of Earth's largest biomes ${ }^{1}$. Here, microorganisms modify volatiles moving between the deep and surface Earth ${ }^{2,3}$. However, it is unknown whether large-scale tectonic processes affect the distribution of microorganisms across this subterranean landscape. We sampled subsurface microbial ecosystems in deeply-sourced springs $^{3}$ across the Costa Rican convergent margin. Noble gases, inorganic and organic carbon isotopes, and photosynthetic biomarkers demonstrate negligible surficial input. Total bacterial community compositions correlate with the major cation and anion compositions of subsurface fluids that are driven by underlying tectonic processes. Co-occurrence networks identify microbial cliques correlating with dissolved carbon compounds, dominated by likely chemolithoautotrophs using the reverse tricarboxylic acid (rTCA) cycle. Metagenomic abundances of rTCA cycle genes also correlate with dissolved inorganic carbon (DIC) across the convergent margin, supporting carbon isotopic evidence ${ }^{3}$ that fixation of slab-derived $\mathrm{CO}_{2}$ into biomass forms the base of a complex subsurface ecosystem. We conclude that subsurface microbial distribution across this convergent margin is ultimately controlled by slab dip angle, tectonic stress regime, carbon volatilization from the slab/mantle source, and the extent of deep subsurface calcite precipitation. Our work establishes a complex feedback whereby the biological processes that alter deep volatile outputs ${ }^{2,3}$ are themselves driven by large-scale tectonic processes. 


\section{Main text:}

The deep subsurface biosphere drives a wide range of key biogeochemical transformations ${ }^{1,2}$, so the composition of microbial communities in subsurface fluids of terrestrial and marine hydrothermal systems has been linked to geochemical parameters such as temperature, $\mathrm{pH}$, redox state, and energy availability ${ }^{2,4-7}$. However, in terrestrial hot springs, this work is often conducted on microbial biofilms and planktonic communities that developed in the presence of sunlight after the fluids emerged at the surface, resulting in a mix of photosynthetic and chemosynthetic processes as recorded in the isotopic composition of organic carbon ${ }^{8}$. While the role of subsurface communities in mediating biogeochemical transformations has been widely investigated ${ }^{1}$, no study has previously addressed how the subsurface biosphere is connected to large-scale geologic settings. For example, variations in microbial community compositions of New Zealand's convergent margin hot springs have been linked to dispersal and local surficial geochemistry ${ }^{9}$, but to our knowledge, no study has investigated potential relationships between microbiology and geochemistry linked to tectonic processes.

Convergent margins connect the vast repository of carbon in the deep Earth with the planetary surface. As denser oceanic plates subduct beneath continental crust, carbon compounds and other volatiles are transferred from Earth's surface to its interior ${ }^{10}$. These compounds are also recycled back to the surface through arc volcanoes and secondary geothermal processes along subduction boundaries ${ }^{10}$. In this dynamic geologic setting, fluid release, magmatism, and deformation provide diverse habitats that may be colonized by microbial assemblages with different preferences for temperature, $\mathrm{pH}$, redox, elemental compositions, pressure, and salinity ${ }^{2}$. While subducting slabs can penetrate $20-150 \mathrm{~km}$, the subsurface biosphere is thought to be limited to the upper few kilometers, where temperatures are below $\sim 150^{\circ} \mathrm{C}^{11}$. Even though they are separated by a large distance, the upward mobility of deeply-sourced fluids may connect subsurface microorganisms to the deep tectonic processes below.

Here we compare bacterial community composition, aqueous and solid phase geochemistry, as well as volatile emissions across the Costa Rican convergent margin (Fig. 1). Here, the Cocos oceanic plate subducts beneath the Caribbean plate at a rate of $80-90 \mathrm{~mm} / \mathrm{yr}^{12}$. The shallow subduction geometry promotes slab dehydration prior to reaching the magma generation zone, allowing for the release of large fluxes of carbon and reduced chemical species into the overlying plate in the outer forearc, forearc, and $\operatorname{arc}^{13}$. Remarkably, the continental extension of the oceanic plate boundary between the East Pacific Rise (EPR) and Cocos Nazca Spreading center (CNS) is identifiable by a shift in the carbon isotopic composition of arc and forearc fluid and gas emissions ${ }^{3}$, suggesting tight coupling between deep tectonic structure and near-surface fluids.

Within the Central American Volcanic Arc (CAVA), only a few hot spring systems have been characterized microbiologically ${ }^{14,15}$. In February 2017, we sampled 21 hot springs across a $>100 \mathrm{~km}$ section of Northern and Central Costa Rica. Fresh fluids venting from the subsurface were collected prior to reaching the surface in order to minimize input from surface microbes. Sediments that accumulated near the outflow source in surface pools of the same springs were also collected. The sites cover a range of subduction provinces from the outer forearc $\left(20-40^{\circ} \mathrm{C}\right.$, $\mathrm{pH}$ 8-10, and 20-40 km slab depth), to the forearc (40-60 ${ }^{\circ} \mathrm{C}, \mathrm{pH} 4-7$, and 40-100 km slab depth), and $\operatorname{arc}\left(>60^{\circ} \mathrm{C}, \mathrm{pH} 0-3 \text {, and } 100-120 \mathrm{~km} \text { slab depth }\right)^{3}$. This includes volcanoes from the 
Northern Guanacaste Geothermal Province, as well as Arenal, Poás and Irazú volcanoes in the Central Cordillera (Figs. 1, S1, and S2, Table S1).

Cell abundances range from $1.5 \times 10^{3}$ to $3.3 \times 10^{6}$ cells $/ \mathrm{mL}$ in the fluids (Table S2), typical of other hydrothermal systems ${ }^{1,5}$. Ten sites produced high-quality bacterial 16S rRNA gene libraries in both fluids and sediments, six were successful only in sediments, and two more only in fluids, comprising 1,933,379 reads after quality control, 33,188 total amplicon sequence variants (ASVs), and 59 phyla (Figs. S3 and S4). Each site contains enriched helium isotope $\left({ }^{3} \mathrm{He} /{ }^{4} \mathrm{He}\right)$ ratios relative to air, suggesting a mix of mantle mantle and slab derived fluids with little input from surface fluids (attributed to high ${ }^{4} \mathrm{He} /{ }^{20} \mathrm{Ne}$ values), and isotopically enriched dissolved inorganic carbon (DIC), derived from a mixture of the oceanic slab and mantle, rather than air ${ }^{3}$. The $\delta^{13} \mathrm{C}$ values of dissolved organic carbon (DOC) correlate positively (Pearson moment correlation $\mathrm{r}^{2}=0.53$, $\mathrm{p}<0.01$ ) with those of slab/mantle-derived DIC (Fig. 1c), rather than with the degree of mixing with surface-derived organic matter ${ }^{3}$. Photosynthetic biomarkers are low in abundance, with $<5 \mu \mathrm{g} / \mathrm{g}$ total photosynthetic pigments in the surface sediments and $<1 \%$ and $<4 \%$ chloroplast-related 16S rRNA genes in fluids and surface sediments, respectively ${ }^{3}$. Altogether, these data suggest that the fluids are deeply-sourced, and primarily contain subsurface microbial communities flushed from a subsurface habitat, similar to cold springs ${ }^{16}$ and deep-sea hydrothermal vents ${ }^{5}$.

Subsurface bacterial community composition varies significantly with geologic province across the subduction zone (outer forearc, forearc, and arc), between the upper plate overlying the EPR and CNS subducted crusts, as well as with the dominant bedrock types (Fig. 1, Table S3, Fig. S5; ADONIS, weighted Jaccard, p < 0.01). Phyla with thermophilic isolates, such as Thermotogae, Aquificae, and candidate phyla Atribacteria and Hydrothermae, increase in relative 16S rRNA gene abundances with increasing temperature and acidity. The opposite trend is observed for Proteobacteria, a few uncultured phyla, Candidatus Cloacimonetes, and others (Figs. 2a, S5, S6, Jaccard similarity Table S4, S5). These results suggest that the microbial community composition is related to subsurface geochemical parameters.

Most phyla, however, do not vary systematically with temperature and pH (Fig. S6), suggesting that the distribution of bacterial communities across this convergent margin is not a simple function of these two parameters (Fig. 3). In order to investigate to what extent the basement rocks and the resulting hydrothermal fluids influence bacterial distribution, we used concentrations of major aqueous anions and cations to categorize the geothermal fluids. A ternary distribution of aqueous anions $\left(\mathrm{Cl}^{-}, \mathrm{SO}_{4}{ }^{2-}\right.$, and DIC, Fig. 2c ${ }^{17}$ distinguishes between: a) acidic (pH 0 to 3) chloride-sulfate waters associated with direct absorption of magmatic gases at arc sites, b) sulfate-poor peripheral geothermal fluids, intermediate in composition between deeply-derived chloride-rich waters and soda springs characteristic of flank volcanic sites and forearc locations, and c) alkaline outer forearc sites, relatively poor in both sulfate and chloride. Aqueous major cations (Fig. 2d; $\mathrm{Mg}^{2+}, \mathrm{Ca}^{2+}$, and $\mathrm{Na}^{+}+\mathrm{K}^{+}$) distinguish between: a) $\mathrm{Ca}^{2+}$-rich acidic arc sites $\left(\right.$ e.g. $\left.{ }^{18}\right)$, b) volcanic flank geothermal sites and forearc springs often associated with travertine deposition ${ }^{3}$, and c) mature deep fluids in equilibrium with feldspars and clays in the outer forearc ${ }^{17}$. Both anion and cation fluid compositions correlate well with total bacterial community compositions (Fig. 2c and 2e; Tables S4 and S5). This suggests that besides variation due to temperature and $\mathrm{pH}$, deep tectonically-controlled geochemical differences correlate with microbial diversity. 
The extent to which geochemical differences influence bacterial distribution and composition across the Costa Rica convergent margin is demonstrated by the stark differences in the distribution of likely sulfur- and iron-oxidizing bacteria. Genera of known iron-oxidizing isolates (like Gallionella, Geobacter and Ferritrophicum) (Fig. S7), are only found at central sites. An iron-oxidizing metabolism for these clades is independently supported by the presence of their mineral product, twisted stalks of iron hydroxide ${ }^{19}$ (Figs. S7, S8). In contrast, genera of known sulfide-oxidizing isolates (like Sulfurihydrogenibium) are found exclusively at northern forearc/arc sites, with the exception of Poás Lake in the Central Cordillera (PL; Fig. S7). We hypothesize that this difference is driven by structural differences between the volcanology of the two areas and it is ultimately connected to the parameters of the subduction of the two plates for the following reasons. The northern sites are mostly located within the the Guanacaste Geothermal Province, where the formation of large calderas at Rincón de la Vieja and Miravalles volcanoes has created sufficient permeability and long-lived heat sources to form extensive high enthalpy hydrothermal systems (Fig. 1a). In Northern Costa Rica the subducting slab angle is significantly steeper than to the south $\left(66^{\circ} \text { vs. } 49^{\circ}\right)^{12}$, resulting in an extensional stress regime and favorable conditions for caldera formation ${ }^{20}$, more permeability in the upper crust, and extensive gas-fluid-rock interactions leading to abundant sulfide generation. In the central region, a shallower subduction angle results in compressional tectonics favoring the formation of large stratovolcanoes with limited permeability in the Central Cordillera ${ }^{21}$. Here, the hydrothermal systems are likely shallower and less extensive than in Northern Costa Rica and sulfur is mostly present in more oxidized forms $\left(\mathrm{SO}_{2}\right.$, sulfuric acid, native sulfur). Large quantities of sulfur are lost through open vent degassing ${ }^{22}$, and $\mathrm{S}$ is more concentrated toward the vents of active volcanoes (like in PL, the single site in the central region with evidence of sulfuroxidizing bacteria). The hot springs surrounding the Central Cordillera stratovolcanoes are enriched in iron leached from acidic water-rock interactions, making iron (II) available for microbial oxidation. In the northern sites, the abundant sulfide may limit iron availability for microbial respiration, since sulfide reacts with iron (II) to form iron-sulfide and pyrite, as suggested by the presence of pyrite framboids (Figs. S7, S8). Altogether, these data suggest that the along-arc crustal structural differences between the two regions, ultimately driven by the dip angle and extensional versus compressional local stress regime ${ }^{21}$, dictate the distribution of sulfur- and iron-oxidizing microbes.

To detect emergent patterns in the distribution of the whole bacterial community relative to deep subsurface geochemistry, we used a co-occurrence network of amplicon sequence variants (ASVs) coupled to Random Forest variable ranking and correlations with Spearman and Pearson statistics (Fig. 3, Tables S6-S11) ${ }^{23}$. This approach allows for the identification of microbial groups, hereafter called cliques, that cohesively respond to variation in geochemical parameters across the dataset. In this way, cliques of functionally redundant or closely interacting microbes can be identified and correlated to subsurface conditions as a group rather than as individuals. We identify ten cliques of co-occurring ASVs (Figs. 3, S9, Tables S6, S7), most of which contain multiple taxa (Fig. S10), comprising $>99 \%$ of the reads in the network analysis (Table S7).

The Random Forest approach identifies correlation with subsurface geochemistry for all cliques with the exception of 6 and 10 (Fig. 3, Tables S8-S11), suggesting a strong link with the underlying geological settings. Clique 10 is not present in enough sites to make cross-site correlations significant, and clique 6 is dominated by Aquabacterium sp. (46\% of the reads) and Alishewanella sp. (22\%), which are common heat-tolerant bacteria from soils ${ }^{24}$ and freshwater ${ }^{25}$. 
Clique 6 therefore acts as an internal negative control, demonstrating that surface-associated bacteria that were washed into the system can be easily identified by their lack of correlation with deep subsurface parameters. Clique 6 comprises $<1 \%$ of the total reads in our dataset.

Carbon availability is the most important factor correlating with the greatest number of cliques. Cliques 9 and 2 are dominated by Thiothrix sp. (65\% of clique 9) and Hydrogenophilaceae (12\% of clique 2), and correlate best with decreasing DIC and increasing $\mathrm{pH}$, respectively (Fig. 3b). Isolates from these clades include chemolithoautotrophic sulfur oxidizers $^{26}$, suggesting their distribution across the arc may be due to affinity for highly limiting DIC concentrations and high $\mathrm{pH}$ in the outer forearc. Clique 4 correlates best with increasing DOC concentrations (Fig. 4b) and is dominated by Sulfurihydrogenibium sp. (55\%) which, along with the other unclassified Hydrogenothermacea sequences in this clique, are related to facultative autotrophic sulfur- and hydrogen-oxidizers that fix carbon using the reverse tricarboxylic acid (rTCA) pathway ${ }^{27}$. Clique 1 correlates more loosely with DOC, which increases in concentration toward the arc, and includes diverse heterotrophic genera able to utilize a variety of anaerobic terminal electron acceptors. Together these cliques contain the majority (57.3\%) of reads in the network, suggesting that across-arc changes in DIC availability are key drivers for microbial community composition.

To investigate whether the correlations between putative chemolithoautotrophs and carbon geochemistry are related to the ability of the microbial community to fix carbon, we conducted a targeted search for metagenomic DNA sequences related to all types of central carbon metabolism across all sites. Co-occurrence network analysis of carbon genes shows that enzymes for three main carbon fixation pathways (rTCA, Calvin-Benson, and WoodLjungdahl ${ }^{28}$ ) cluster in statistically robust cliques around their key genes (Fig 4a, S12, Table $\mathrm{S} 12)$. Clique B, containing almost all the rTCA genes including the key genes encoding for ATPcitrate lyase (as well as its alternative citryl-CoA lyase ${ }^{29}$ ) and 2-oxoglutarate synthase (Fig. 4c), is the only clique that correlates consistently with subsurface geochemical parameters (Fig. 4b, S11-S12, Tables S13-S15). Across all statistical tests (Tables S13-S15), clique B correlates best with DIC, suggesting a strong relationship between DIC and rTCA-based chemolithoautotrophy.

Our microbial community analyses show that 1 ) cliques containing known rTCAutilizing chemolithoautotrophic genera correlate best with DOC concentrations, consistent with these organisms contributing significantly to the DOC pool; 2) members of known heterotrophic genera also correlate with DOC, suggesting that chemosynthetically-derived organic matter stimulates secondary consumers; 3) most genes in the rTCA pathway, including those encoding key enzymes, form a statistically-significant clique, consistent with them being used together in the rTCA pathway; and 4) the rTCA gene clique correlates best with DIC concentrations, consistent with higher DIC concentrations stimulating more rTCA-based chemolithoautotrophy. Our geochemical analyses show that 1 ) the entire DIC pool was initially derived from a deep subsurface slab/mantle source, which was subsequently modified by varying amounts of $\mathrm{CO}_{2}$ loss from deep calcite deposition $\left.{ }^{3} ; 2\right)$ the entire DOC pool has a $\Delta^{13} \mathrm{C}_{\text {DIC-DoC }}$ value $(-8.7 \pm 1.3 \%$ ) in the range of the measured fractionation factors for rTCA (-2 to $-12 \%)^{28}$ (Fig. 1); and 3) concentrations of DOC correlate with concentrations of DIC, suggesting that more DOC is produced when more DIC is available. Together, these findings suggest that the ecosystem is driven primarily by chemolithoautotrophic biomass production through the rTCA cycle, dependent on the supply of DIC from deeply-sourced fluids rising from the slab/mantle after subsequently undergoing calcite precipitation. Given reasonable estimates of cell turnover time 
and carbon content (Methods), we estimate that 500 to 2,000 years would be required to produce the entire DOC pool from chemolithoautotrophy. Fluid residence times in hot springs (100 to 100,000 years $^{30}$ ) are commonly sufficiently long for this to occur. Precedent for chemolithoautotrophically-based ecosystems comes from metagenomic, metatranscriptomic, and metaproteomic data in oligotrophic (DOC $<30 \mu \mathrm{M}$ ) deep subsurface aquifers ${ }^{6,7}$. Our work shows that such chemolithoautotrophically-based ecosystems can fuel much greater DOC production ( $>1 \mathrm{mM}$ ) across an active convergent margin.

We conclude that the subsurface microbial community of a $\sim 400 \mathrm{~km}$ subduction segment in Costa Rica cohesively responds to geochemical signals that can ultimately be traced to deep tectonic processes (Fig. 2). This subsurface biosphere landscape varies along the convergent margin, through changes in supply of redox-active substrates, as well as across the convergent margin, through changes in the supply of DIC to a chemosynthetically-based ecosystem. Collectively, our work shows that volatiles and elements mobilized from the descending slab and mantle can be significantly altered by interaction with the deep subsurface biosphere on their trek back to the surface, resulting in a previously unrecognized coupling between geological and biological feedbacks in a convergent margin, with significant implications for the understanding of carbon reservoir changes in deep time.

\section{References:}

1. Magnabosco, C. et al. The biomass and biodiversity of the continental subsurface. Nat. Geosci. 11, 707-717 (2018).

2. Merino, N. et al. Living at the Extremes: Extremophiles and the Limits of Life in a Planetary Context. Front. Microbiol. 10, 780 (2019).

3. Barry, P. H. et al. Forearc carbon sink reduces long-term volatile recycling into the mantle. Nature 568, 487-492 (2019).

4. Colman, D. R. et al. Geobiological feedbacks and the evolution of thermoacidophiles. ISME J. 12, 225-236 (2018).

5. Reveillaud, J. et al. Subseafloor microbial communities in hydrogen-rich vent fluids from hydrothermal systems along the Mid-Cayman Rise. Environ. Microbiol. 18, 1970-1987 (2016).

6. Lau, M. C. Y. et al. An oligotrophic deep-subsurface community dependent on syntrophy is dominated by sulfur-driven autotrophic denitrifiers. Proc. Natl. Acad. Sci. USA E7927-E7936 (2016).

7. Momper, L., Jungbluth, S. P., Lee, M. D. \& Amend, J. P. Energy and carbon metabolisms in a deep terrestrial subsurface fluid microbial community. ISME J. 11, 2319-2333 (2017).

8. Havig, J. R., Raymond, J., Meyer-Dombard, D. R., Zolotova, N. \& Shock, E. L. Merging isotopes and community genomics in a siliceous sinter-depositing hot spring. J. Geophys. Res. Biogeosciences 116, 1-15 (2011).

9. Power, J. F. et al. Microbial biogeography of 925 geothermal springs in New Zealand. Nat. Commun. 9, 2876 (2018).

10. Kelemen, P. B. \& Manning, C. E. Reevaluating carbon fluxes in subduction zones, what goes down, mostly comes up. Proc. Natl. Acad. Sci. 112, E3997-E4006 (2015). 
11. Plümper, O. et al. Subduction zone forearc serpentinites as incubators for deep microbial life. Proc. Natl. Acad. Sci. USA 114, 4324-4329 (2017).

12. Syracuse, E. M. \& Abers, G. A. Global compilation of variations in slab depth beneath arc volcanoes and implications. Geochem. Geophys. Geosystems 7, Q05017 (2006).

13. Shaw, A. M., Hilton, D. R., Fischer, T. P., Walker, J. A. \& Alvarado, G. E. Contrasting He-C relationships in Nicaragua and Costa Rica: Insights into $\mathrm{C}$ cycling through subduction zones. Earth Planet. Sci. Lett. 214, 499-513 (2003).

14. Arce-Rodríguez, A. et al. Thermoplasmatales and sulfur-oxidizing bacteria dominate the microbial community at the surface water of a CO2-rich hydrothermal spring located in Tenorio Volcano National Park, Costa Rica. Extremophiles 23, 177-187 (2019).

15. Crespo-Medina, M. et al. Methane dynamics in a tropical serpentinizing environment: The Santa Elena ophiolite, Costa Rica. Front. Microbiol. 8, 916-916 (2017).

16. Probst, A. J. \& Moissl-eichinger, C. “Altiarchaeales”: Uncultivated Archaea from the Subsurface. 1381-1395 (2015).

17. Giggenbach, W. F. Geothermal solute equilibria. Derivation of Na-K-Mg-Ca geoindicators. Geochim. Cosmochim. Acta 52, 2749-2765 (1988).

18. Rodríguez, A. \& van Bergen, M. J. Superficial alteration mineralogy in active volcanic systems: An example of Poás volcano, Costa Rica. J. Volcanol. Geotherm. Res. 346, 54-80 (2017).

19. Chan, C. S., Fakra, S. C., Emerson, D., Fleming, E. J. \& Edwards, K. J. Lithotrophic iron-oxidizing bacteria produce organic stalks to control mineral growth: implications for biosignature formation. ISME J. 5, 717-727 (2011).

20. Lücke, O. H. \& Arroyo, I. G. Density structure and geometry of the Costa Rican subduction zone from 3-D gravity modeling and local earthquake data. Solid Earth 6, 11691183 (2015).

21. Protti, M., Gündel, F. \& McNally, K. The geometry of the Wadati-Benioff zone under southern Central America and its tectonic significance: results from a high-resolution local seismographic network. Phys. Earth Planet. Inter. 84, 271-287 (1994).

22. de Moor, J. M. et al. A new sulfur and carbon degassing inventory for the Southern Central American Volcanic Arc: The importance of accurate time-series data sets and possible tectonic processes responsible for temporal variations in arc-scale volatile emissions: New volatile budget for Central America. Geochem. Geophys. Geosystems 18, 4437-4468 (2017).

23. Delgado-Baquerizo, M. et al. A global atlas of the dominant bacteria found in soil. Science 359, 320-325 (2018).

24. Kim, M.-S., Jo, S. K., Roh, S. W. \& Bae, J.-W. Alishewanella agri sp. nov., isolated from landfill soil. Int. J. Syst. Evol. Microbiol. 60, 2199-2203 (2010).

25. Chen, W.-M. et al. Aquabacterium limnoticum sp. nov., isolated from a freshwater spring. Int. J. Syst. Evol. Microbiol. 62, 698-704 (2012).

26. Garrity, George M. \& Bell, J. A. Hydrogenophilaceae fam. nov. in Bergey’s Manual of Systematics of Archaea and Bacteria (American Cancer Society). 
27. Hayashi, N. R., Ishida, T., Yokota, A., Kodama, T. \& Igarashi, Y. Hydrogenophilus thermoluteolus gen. nov., sp. nov., a thermophilic, facultatively chemolithoautotrophic, hydrogen-oxidizing bacterium. Int. J. Syst. Evol. Microbiol. 49, 783-786 (1999).

28. Berg, I. A. et al. Autotrophic carbon fixation in archaea. Nat. Rev. Microbiol. 8, 447-460 (2010).

29. Giovannelli, D. et al. Insight into the evolution of microbial metabolism from the deepbranching bacterium, Thermovibrio ammonificans. eLife 6, (2017).

30. Yokochi, R. et al. Noble gas radionuclides in Yellowstone geothermal gas emissions: A reconnaissance. Chem. Geol. 339, 43-51 (2013).

31. Vetriani, C., Jannasch, H. W., Gregor, B. J. M. A. C., Stahl, D. A. \& Reysenbach, A. Population structure and phylogenetic characterization of marine benthic Archaea in deep-sea sediments. Appl. Environ. Microbiol. 65, 4375-4384 (1999).

32. Wright, J. J., Lee, S., Zaikova, E., Walsh, D. A. \& Hallam, S. J. DNA extraction from $0.22 \mu \mathrm{m}$ Sterivex filters and cesium chloride density gradient centrifugationcs. 3-6 (2009).

33. Teare, J. M. et al. Measurement of nucleic acid concentrations using the DyNA Quant ${ }^{\mathrm{TM}}$ and the GeneQuant ${ }^{\mathrm{TM}}$. BioTechniques 22, 1170-1174 (1997).

34. Simbolo, M. et al. DNA qualification workflow for next generation sequencing of histopathological samples. PLoS ONE 8, e62692 (2013).

35. Giovannelli, D. et al. Diversity and distribution of prokaryotes within a shallow-water pockmark field. Front. Microbiol. 7, (2016).

36. Huse, S. M. et al. Comparison of brush and biopsy sampling methods of the ileal pouch for assessment of mucosa-associated microbiota of human subjects. Microbiome 2, 5 (2014).

37. Huse, S. M. et al. VAMPS: a website for visualization and analysis of microbial population structures. BMC Bioinformatics 15, 41 (2014).

38. Schloss, P. D. et al. Introducing mothur: Open-source, platform-independent, community-supported software for describing and comparing microbial communities. Appl. Environ. Microbiol. 75, 7537-7541 (2009).

39. Quast, C. et al. The SILVA ribosomal RNA gene database project: improved data processing and web-based tools. Nucleic Acids Res. 41, D590-D596 (2012).

40. Zhu, C. et al. Functional sequencing read annotation for high precision microbiome analysis. Nucleic Acids Res. 46, (2018).

41. $\quad \mathrm{R}$ Core Team. $R$ : A language and environment for statistical computing. (R Foundation for Statistical Computing, 2013).

42. McMurdie, P. J. \& Holmes, S. phyloseq: An R Package for Reproducible Interactive Analysis and Graphics of Microbiome Census Data. PLoS ONE 8, e61217 (2013).

43. Oksanen, J. Package 'vegan'. (CRAN, 2019).

44. Hamilton, N. E. \& Ferry, M. ggtern: Ternary diagrams using ggplot2. J. Stat. Softw. 87, (2018).

45. Stekhoven, D. J. \& Buhlmann, P. MissForest--non-parametric missing value imputation 
for mixed-type data. Bioinformatics 28, 112-118 (2012).

46. Genuer, R., Poggi, J.-M. \& Tuleau-Malot, C. VSURF: An R package for variable selection using random forests. $R$ J. 7, 19 (2015).

47. Wickham, H. ggplot2: elegant graphics for data analysis. (Springer, 2009).

48. Sheik, C. S. et al. Identification and removal of contaminant sequences from ribosomal gene databases: Lessons from the Census of Deep Life. Front. Microbiol. 9, 840-840 (2018).

49. Sugimori, K. et al. Microbial life in the acid lake and hot springs of Poas Volcano, Costa Rica. Colima Volcano Int. Meet. (2002).

50. Giovannelli, D. et al. Large-Scale Distribution and Activity of Prokaryotes in Deep-Sea Surface Sediments of the Mediterranean Sea and the Adjacent Atlantic Ocean. PLoS ONE 8, 1-15 (2013).

51. Giggenbach, W. F. \& Soto, R. C. Isotopic and chemical composition of water and steam discharges from volcanic-magmatic-hydrothermal systems of the Guanacaste Geothermal Province, Costa Rica. Appl. Geochem. 7, 309-332 (1992).

52. Csardi, G. \& Nepusz, T. The igraph software package for complex network research. Inter Journal Complex Systems, (2006).

53. Bolger, A. M., Lohse, M. \& Usadel, B. Trimmomatic: a flexible trimmer for Illumina sequence data. Bioinformatics 30, 2114-2120 (2014).

54. Hoehler, T. M. \& Jørgensen, B. B. Microbial life under extreme energy limitation. Nat. Rev. Microbiol. 11, 83-94 (2013).

Acknowledgments: This work is part of the Biology Meets Subduction project, a collaboration of 46 researchers from 19 institutions from 9 nationalities. We thank Patricia Barcala Dominguez for assistance with figure illustrations, and Tori Hoehler for helpful comments. Funding: This work was principally supported by grant G-2016-7206 from the Alfred P. Sloan Foundation and the Deep Carbon Observatory to P.H.B., J.M.dM, D.G, and K.G.L, with DNA sequencing support from the Census of Deep Life. In addition, K.G.L. was supported by NSF OCE-1431598, NASA Exobiology NNX16AL59G, and Simons Foundation 404586. P.H.B. was supported by NSF grant 1144559 during a portion of this project. J.M.d.M. was supported by NSF 1850699 during a portion of the project. D.G. and C.V. were supported by an NSF grant (MCB 1517567) and D.G. was supported by an ELSI Origins Network (EON) research Fellowship, which is supported by a grant from the John Templeton Foundation, and a Deep Life Modeling and Visualization Fellowship from the Deep Carbon Observatory. G.L.J. was supported by FONDECYT Grant 11191138 (ANID Chile). D.G., S.M.M. and J.B. acknowledge the support of the project ENIGMA (NASA Astrobiology Institute cycle 8) Grant Number 80NSSC18M0093. The opinions expressed in this publication are those of the authors and do not necessarily reflect the views of the John Templeton Foundation. This work was further supported in part by JSPS KAKENHI grants (JP17K14412, JP17H06105, JP17H02989) awarded to M.N., and M.Y. was supported by a DEKOSIM grant (BAP-08-11-DPT.2012K120880), financed by the Strategy and Budget Ministry of Turkey. Author contributions: K.F. and K.G.L. wrote the original draft and performed initial data analyses. Conceptualization and funding acquisition were performed by P.B., J.M.dM., D.G., and K.G.L. Formal analysis and visualization were performed by K.F. and 
D.G. Investigations and data acquisition were performed by K.F., M.Y., E.M., G.D., D.F., M.DC., F.R., M.N., F.S., H.M., S.M.M., T.J.R., M.B., J.B., D.G. Writing and editing of the final draft was performed by M.O. S., M.Y., M.N., C.V., C. R., G. L. J., H.M., T. J. R., M. M., J.B., J.M.dM., P.H.B., D.G., and K.G.L. Competing interests: Authors declare no competing interests. Materials and Correspondence: D. G. and K. L. (onato.giovannelli@unina.it and klloyd@utk.edu)

\section{Materials and Methods}

Data and analysis availability

A complete R script containing all the steps to reproduce our analysis is available at https://github.com/dgiovannelli/SubductCR_16S-diversity.git and released as a permanent version using Zenodo under the DOI: https://doi.org/10.5281/zenodo.3483104. This Targeted Locus Study project has been deposited at DDBJ/EMBL/GenBank under the accession KEBJ00000000, with project ID PRJNA579365. The version described in this paper is the first version, KEBJ01000000. Metagenomic data are in the NCBI SRA with project ID PRJNA627197. All other data is available in the main text or the supplementary materials.

\section{Location and Sample Collection}

At each sampling site, 0.5 to 1.5 liters of hydrothermal fluids were filtered through Sterivex $0.22 \mu \mathrm{m}$ filter cartridges (MilliporeSigma) and $15 \mathrm{ml}$ falcon tubes were filled with sediments. Both filters and sediment-filled tubes were immediately frozen onsite at liquid nitrogen temperature in a cryogenic dry shipper (ThermoFisher Scientific, Arctic Express 20) for transport back to the home laboratory. A description of the sites and their GPS coordinates were described previously ${ }^{1,2}$. Field sampling for trace metals in the fluids was carried out by fixing a filtered $(0.22 \mu \mathrm{m})$ sub-sample in $5 \% \mathrm{HNO}_{3}$; filtered $(0.22 \mu \mathrm{m})$ sub-samples were also taken for major ion measurements. Samples for the determination of trace elements in the solid fraction were sampled in $15 \mathrm{ml}$ falcon tubes and stored frozen. Sediments were also sampled for mineralogical analyses, while samples for scanning electron microscopy and cell counts were fixed in $3 \%$ formaldehyde and kept at $+4^{\circ} \mathrm{C}$.

\section{DNA extraction}

DNA extractions from Sterivex filters were performed using a modified phenol-chloroform extraction optimized for low biomass samples based on previously published methods ${ }^{31}$, with additional modifications for use with Sterivex filters as described previously ${ }^{32}$. Briefly, extractions were performed via chemical lysis with lysozyme, proteinase $\mathrm{K}$, and SDS treatment then purified with phenol-chloroform extractions and precipitation with sodium acetate and isopropyl alcohol. Initial extractions from sediment samples were performed using the Qiagen DNeasy PowerSoil HTP 96 Kit, with additional extractions performed using the modified phenol-chloroform extraction described above, followed by concentration using the Zymo Genomic DNA Clean \& Concentrator Kit. Extracted DNA was quantified using a NanoDrop 2000c (ThermoFischer Scientific) with additional PCR screening performed using universal bacterial primers ${ }^{33,34}$. 


\section{Sedimentary Organic Matter}

Total protein, carbohydrate, lipid, chlorophyll-a, and phaeopigments were determined as previously described ${ }^{35}$. Concentrations were calculated using standard curves, and normalized to sediment dry weight after desiccation $\left(60^{\circ} \mathrm{C}, 24 \mathrm{~h}\right)$. Protein, carbohydrate, and lipid concentrations were converted into carbon (C) equivalents using the conversion factors of 0.49 , 0.40 , and $0.75 \mu \mathrm{gC} / \mu \mathrm{g}$ dry weight, respectively. Chloroplastic pigment equivalents are defined here as the sum of the chlorophyll-a and phaeopigment concentrations.

\section{Geochemistry}

Data for the carbon isotope analysis of dissolved inorganic carbon (DIC) and dissolved organic carbon (DOC), the concentration of sedimentary aliphatic hydrocarbons and polycyclic aromatic hydrocarbons were previously reported ${ }^{3}$ along with the methods used to quantify them. Concentrations of anions were determined using a Dionex AS4A-SC separation column, sodium hydroxide eluent and ASRS-I suppressor. For cations a Dionex CS12-SC separation column was used, with methane sulfonic acid eluent and CSRS-I suppressor. Trace metal concentrations were determined in aqueous and acid-digested solid samples with a NexIon 350X ICP-MS instrument. Total acid digestion included microwave-assisted digestion of dry sediments with nitric acid $\left(16 \mathrm{~N} \mathrm{HNO}_{3}\right)$ and suprapure hydrofluoric acid (HF) and boric acid. The calibration standards were prepared by using Perkin Elmer multi-element calibration standard solution of metals (including Fe, Al, As, Mn, Mg, K, V, Cr, Co, Ni, Ca, Mg, Se, Sr, Ga, Ba, Be, Pb, Cs) in 5\% $\mathrm{HNO}_{3}$ with concentration of $10 \mu \mathrm{g} / \mathrm{ml}$ each element. Internal yttrium standard was added in each sample before analysis to correct the intensity deviations during measurement with ICP-MS. The molar concentration of each element was calculated by a standard calibration curve of each element with multiplying by volume, dilution and dividing by molar mass.

\section{Flow Cytometry}

Fluids ( $1 \mathrm{ml}$ ) obtained directly from the source were placed into a $2 \mathrm{ml}$ plastic tube with a rubber o-ring screwcap (to prevent evaporation) containing $500 \mu \mathrm{l} 3 \%$ paraformaldehyde solution in phosphate-buffered-saline (PBS). Cell count samples were kept at room temperature during return to the University of Tennessee and were weighed upon returning to the lab. Cell counts were determined on a Guava Easy Cyte 6HT-2L (Millipore) flow cytometer. Triplicate aliquots of each sample $(200 \mu \mathrm{l})$ were stained with $5 \times$ SybrGreen prior to analysis. Gating strategy was optimized using stained, unstained, and filtered controls.

\section{Scanning electron microscopy}

Scanning electron microscopy (SEM) micrographs of the hydrothermal sediments were obtained on a Phenom ProX scanning electron microscope at 10 and $15 \mathrm{kV}$ and using a charge reduction sample holder at Rutgers University. Samples were previously dried at $40^{\circ} \mathrm{C}$ for 24 hours before imaging, and mounted using conductive carbon tape on a sample pin. The same instrument was used at $15 \mathrm{kV}$ to perform Energy Dispersive X-Ray Spectroscopy (EDX) for elemental analysis of particles in the samples. 
$\underline{\text { X-ray diffraction and Raman spectroscopy }}$

Each sediment sample was dried at $50^{\circ} \mathrm{C}$ for 24 hours. A representative portion of each sample was ground to $<10$ um grain size with an alumina mortar and pestle. The ground sample material was analyzed with Bruker D8 powder X-ray diffractometer, with a Cu source (1.5406 $\mathrm{nm}$ ) and 2-theta range of $5^{\circ}$ to $70^{\circ}$ at $0.01^{\circ}$ increments. Bruker Eva software was used to identify mineral phases with pattern search-match performed on the RRUFF database (http://www.rruff.info/) and AMCSD (http://rruff.geo.arizona.edu/) pattern libraries. Raman spectroscopy was performed on selected samples. The crystals were randomly oriented and the Thermo Almega microRaman system was set at 100\% power, using a $532 \mathrm{~nm}$ solid-state laser and a thermoelectrically cooled CCD detector. The laser was partially polarized with $4 \mathrm{~cm}-1$ resolution and a spot size of $1 \mu \mathrm{m}$. Phase identification was performed using the search-match routines available in the Thermo Almega Omnic and CrystalSleuth software against the RRUFF database Raman spectra library. Trimming and background removal was performed with CrystalSleuth software.

Sequence processing and statistical analysis

Extracted DNA was sequenced for the analysis of the bacterial diversity after amplifying the bacteria-specific V4-V5 region of the 16S rRNA gene using primers 518F (AATTGGANTCAACGCCGG) and B1048R (CGTCTGCCATGYACCWC). The same extracted DNA was used for shotgun metagenomic sequencing without amplification. Sequencing was performed as part of the Census of Deep Life initiative within the Deep Carbon Observatory and performed at the Marine Biological Laboratory sequencing facility (https://www.mbl.edu/) on an Illumina MiSeq platform for amplicons and an Illumina NextSeq platform for metagenomes. Amplicon sequences were screened for quality, including chimerachecking with UCHIME, by the MBL as previously described and high- quality merged sequences were published on the Visualization and Analysis of Microbial Population Structures (VAMPS) website ${ }^{36,37}$. Obtained reads were processed using mothur ${ }^{38}$, following the Miseq standard operating procedure using amplicon sequence variants (ASVs) rather than operational taxonomic units. Taxonomy was assigned using the RDP naive bayesian classifier against the Silva v132 release $^{39}$. Metagenomic reads were annotated using Mifaser ${ }^{42}$ using the GS+ database available here (https://bromberglab.org/project/mifaser/) that includes gene sequences from biogeochemically relevant pathways.

All statistical analyses, data processing and plotting were carried out in the R statistical software $3.6^{41}$, using the phylose ${ }^{42}$, vegan ${ }^{43}$, ggtern $^{44}$, missForest ${ }^{45}$, VSURF $^{46}$ and ggplot2 ${ }^{47}$ packages. A complete R scrip containing all the step to reproduce our analysis is available at https://github.com/dgiovannelli/SubductCR_16S-diversity.git and released as a permanent version using Zenodo under the DOI: https://doi.org/10.5281/zenodo.3483104. Briefly, the obtained count table, taxonomy assignment and phylogenetic tree were combined together with the environmental variables into a phyloseq object. Low prevalence ASVs, mitochondria and chloroplast-related sequences and potential contaminants were removed (described in more detail below, Fig. S3). In both fluids and sediments, common laboratory contaminants from DNA processing, feces, and skin ${ }^{48}$ were largely absent $(<0.04 \%$ in the entire dataset and less than $0.01 \%$ in any individual library), and no ASV was shared by all samples. Acinetobacter sp., a 
group containing hospital-acquired pathogens as well as environmental clades ${ }^{49}$, was in high abundance (between 20 and 60\% of the reads) in three samples of hydrothermal water collected in spas/resorts, and was removed from further analysis. The remaining ASVs represented $\sim 81 \%$ of the original reads. In total 1,933,379 reads and 33,188 ASVs were retained after the preprocessing steps.

Obtained results were used for diversity plots and for multivariate analysis. The basic approach involved non-metric multidimensional scaling (nMDS) using Jaccard and Unifrac distances (the latter both weighted and unweighted) to identify similarity in bacterial diversity community composition across the sampled stations as previously described ${ }^{35,50}$. nMDS ordinations were used to identify potential environmental explanatory variables using linear correlations of environmental vectors with the envfit function in vegan. The roles of different sampling factors in influencing the observed community patterns were tested using a permutation distance-based approach using the adonis function of the vegan package. Tested factors included the sample matrix type (type: fluids, sediments), the subducting plate (plate: EPR or CNS), the location of the sampling site along the volcanic arc (province: outer forearc, forearc, arc), the geological province based on the map reproduced in Fig. 1 (geol_prov: 1, 2, 3 and 4), dominant basement rock type obtained from the USGS Mineral Resources GIS maps (49) (rocks), and the volcanic area the sampling sites is located in (volcano: forearc and the name of the major Costa Rica volcanoes). Additionally, two factors (anions and cations) were obtained based on the ternary plot of the aqueous geochemical composition of the fluids at each site as presented in Fig. 2b and 2d. The sampled sites were classified using their position in these plots, based on their geochemical composition, their interaction with different underlying basement rocks and the degree of equilibration ${ }^{17,51}$.

Dominant ASVs were obtained by adding a further step of prevalence filtering, removing all the ASVs with a global abundance of less than 20 reads and present in less than 3 samples. This step reduced the number of ASVs to about $12 \%$ of the original variants, while retaining $\sim 73 \%$ of the total reads. The diversity plots were inspected to ensure that no major changes in the dominant phylotypes and taxonomic groups were introduced (Fig. S4). At this step PL was removed from the dataset because it was the only sample representing a hyperacidic volcanic crater lake, and was therefore an outlier in the nMDS analysis (Fig. 2). A co-occurrence network was constructed based on pairwise Spearman rank correlations among the ASVs across the entire dataset. Only positive correlations with a Spearman's correlation coefficient $(\rho)>0.65$ were retained, as they provide information on microbial phylotypes that may respond similarly to environmental conditions. The network we recovered included 3,935 nodes with 339,803 edges. The topology of the obtained network was investigated and a modularity analysis using a number of clustering algorithms built in the R package igraph ${ }^{52}$ was performed (random walks, label propagation and Louvain clustering algorithms). While the total number of clusters changed, the main clusters identified by the tested algorithms converged, and the 10 clusters identified by the Louvain clustering algorithms were retained for downstream analysis. Identified clusters represented ecological cliques of phylotypes showing a cohesive distribution across the sampled hot springs. The relationship between each clique's cumulative abundance and environmental predictors was investigated using a Random Forests (RF) regression analysis. The analysis was carried out using the VSURF package. Clique abundances were re-scaled using z-scores before the RF analysis and missing environmental observations were imputed using the missForest package. To further test the validity of the identified environmental predictors the cumulative abundance of each clique was correlated using both Pearson moment correlation and Spearman 
rank correlation against all the environmental predictors. A conservative $p$ level of $p<0.01$ was selected for all statistical tests performed ${ }^{55}$. Correlations were also manually inspected using scatterplots, to identify possible non-linear relationships and confirm correlations identified with statistical testing. The variables identified by each different approach (RF analysis, scatterplots inspection, Pearson moment correlation and Spearman rank correlation) overlapped significantly. The most informative environmental variable associated with the distribution of each clique was selected for plotting in Fig. 3b.

After trimming with Trimmomatic ${ }^{53}$, metagenomic short reads were processed with Mifaser $^{40}$. The relative abundance for each enzyme was calculated by dividing the raw abundance value by the total number of enzyme counts for each sample. Enzyme abundance was then normalized to library size by multiplying the relative abundance by the median library size (65,709,491 bp). Cliques were obtained from pairwise spearman correlations and investigated for their relationship with environmental parameters using the same approach described for the ASV cliques.

Estimates of total residence time required for the total cellular biomass to be converted to the observed DOC were made with the following:

$$
\frac{t_{2} \times[D O C]}{[\text { cells }] \times f_{\text {autotroph }} \times C_{\text {cells }}} \quad \text { Eq. } 1
$$

where $t_{2}$ is the turnover time of the population, [DOC] is the concentration of dissolved organic carbon, [cells] is the concentration of cells, $\mathrm{f}_{\text {autotoroph }}$ is the fraction of cells that are autotrophs, and $\mathrm{C}_{\text {cells }}$ is the carbon content of microbial cells. One year was used for $\mathrm{t}_{2}$ based on the slowest estimates for the upper meter of marine sediments ${ }^{54}$. In marine sediments, populations are buried at measurable rates, so unlike hot spring fluids, they are amenable to measuring microbial biomass turnover times. Microbes in hot springs have faster turnover times than in marine sediments, due to advective fluxes of nutrients in hot springs, so the 1 year estimate is conservative. Values for [DOC] and [cells] $\left(0.67 \mathrm{mmol} / \mathrm{L}\right.$ and $6.2 \times 10^{5}$ cells $/ \mathrm{ml}$, respectively) were the average for all eight sites where both measurements were obtained, excluding SL, which had extremely high [DOC] values $(6.29 \mathrm{mmol} / \mathrm{L})$ and little evidence for chemolithoautotrophy since DOC was more ${ }^{13} \mathrm{C}$-enriched than DIC $\left(\delta^{13} \mathrm{C}\right.$ values of -0.65 for

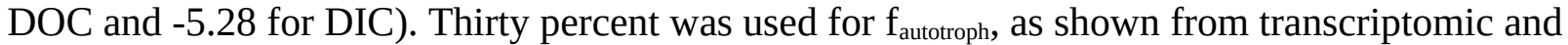
proteomic data from the deep terrestrial subsurface 6 . Two values were used for $\mathrm{C}_{\text {cells, }}, 23 \mathrm{fgC} / \mathrm{cell}$, based on extremely energy-starved marine sediment populations ${ }^{4}$, and $88 \mathrm{fgC} / \mathrm{cell}^{5}$. These two values account for the range of residence times reported in the main text. 
a

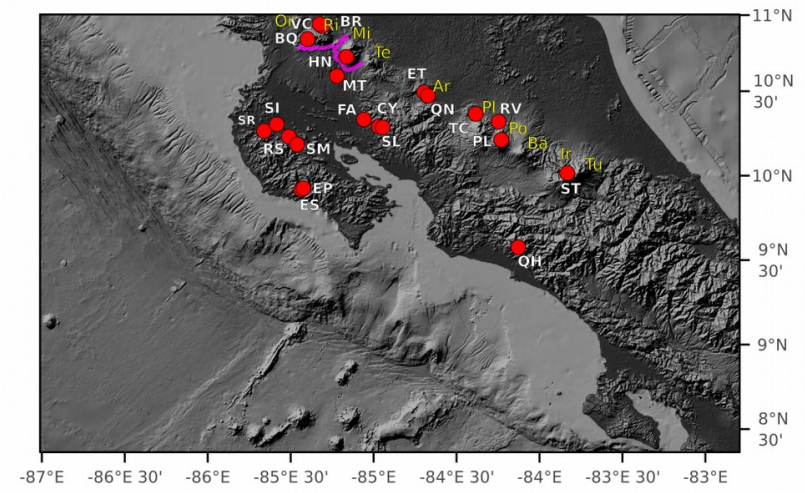$$
\text { C }
$$

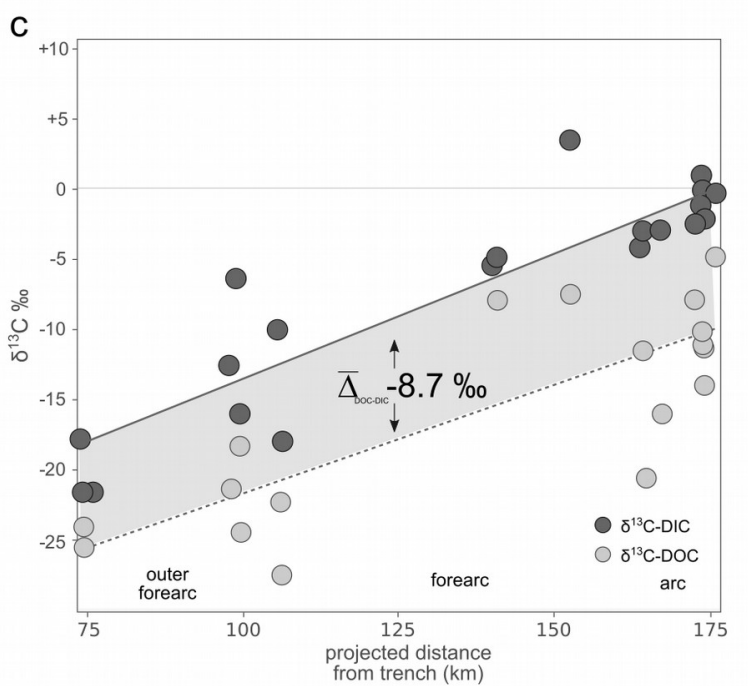

b

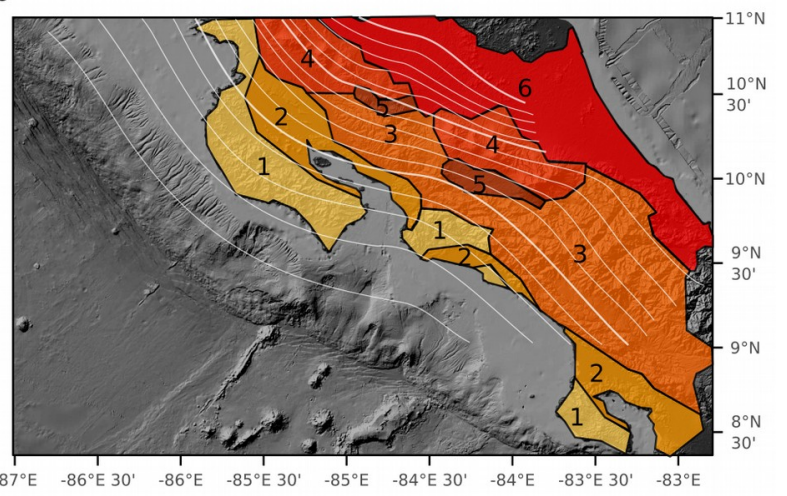

d

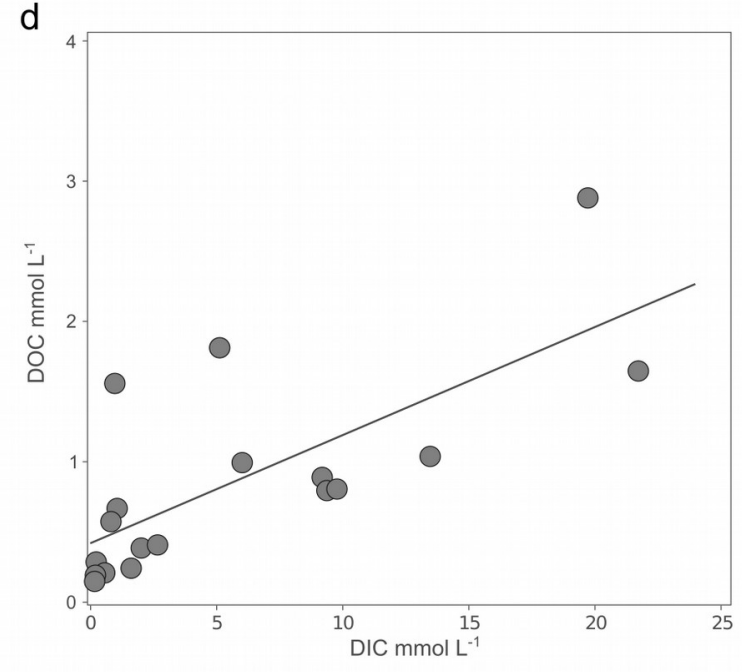

Figure 1. The sampled sites cover a wide range of geological provinces across the Costa Rican convergent margin, and have correlated $\delta^{13} \mathrm{C}$ values and concentrations of dissolved inorganic carbon (DIC) and dissolved organic carbon (DOC). a) Locations of the sampled hot springs and volcanic crater lake (red markers with white labels), volcanoes (yellow labels), and the calderas of the Guanacaste Geothermal Province (purple lines, adapted from Tassi et al., 2018). b) subducting slab depth lines (thin lines every $10 \mathrm{~km}$ depth, thick lines every $50 \mathrm{~km}$ depth) and principal bedrock types: 1 Cretaceous-Tertiary ophiolites; 2 - Tertiary basins; 3 - Tertiary volcanic range; 4 - Quaternary volcanic range; 5 - Intra-arc basins; 6- Caribbean coastal plain (adapted from Tassi et al., 2004). c) $\delta^{13} \mathrm{C}$ values of DIC and DOC show similar spatial trends with the projected distance from the trench $\left(\mathrm{R}^{2}\right.$ of 0.81 and 0.65 , for DIC and DOC, respectively) with an average offset ( $\Delta_{\text {DoC-DIC }}$ ) of $-8.7 \pm 1.3 \%$ o. d) Concentrations of DOC and DIC correlate with each other (Pearson moment correlation $\mathrm{R}^{2}=0.53, \mathrm{p}<$ 0.01) across the sampled sites (SL is off-scale with $5.69 \mathrm{mmol} \mathrm{L}^{-1} \mathrm{DIC}$ and $6.29 \mathrm{mmol} \mathrm{L}^{-1} \mathrm{DOC}$ ). Data in (c) and (d) were used in previously published calcite precipitation models (Barry et al. 2019). 

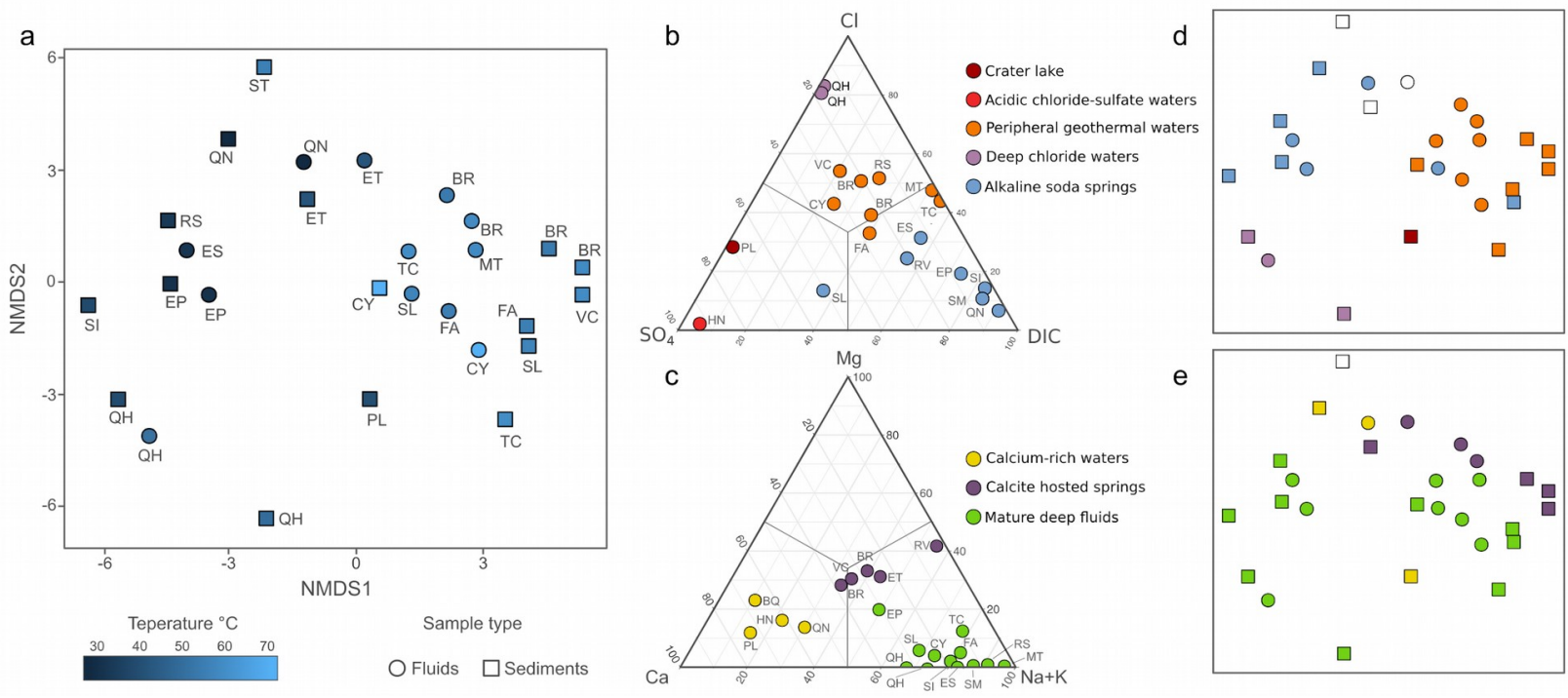

Figure 2. Clustering of the sites based on microbial community diversity and geochemical characteristics. a) Non-metric multidimensional scaling (nMDS, stress 0.17) plot of the 16S rRNA gene amplicon microbial diversity based on Jaccard dissimilarity measure in the fluids (circles) and sediments (squares), colored by spring temperature, with sample names corresponding to those of Fig. 1; b and c) Ternary diagrams showing the clustering of the samples based on the major anions (a) and major cations (c). $\mathbf{d}$ and e) - same nMDS plot from (a), but colored according to the geochemistry-based grouping from (b) (anions, ADONIS $\mathrm{p}<0.001$ ) and (d) (cations, ADONIS $\mathrm{p}<0.001$ ), respectively. Empty symbols in (d) and (e) represent samples for which one or more ions were missing, and therefore have no placement in (b) and (c). 

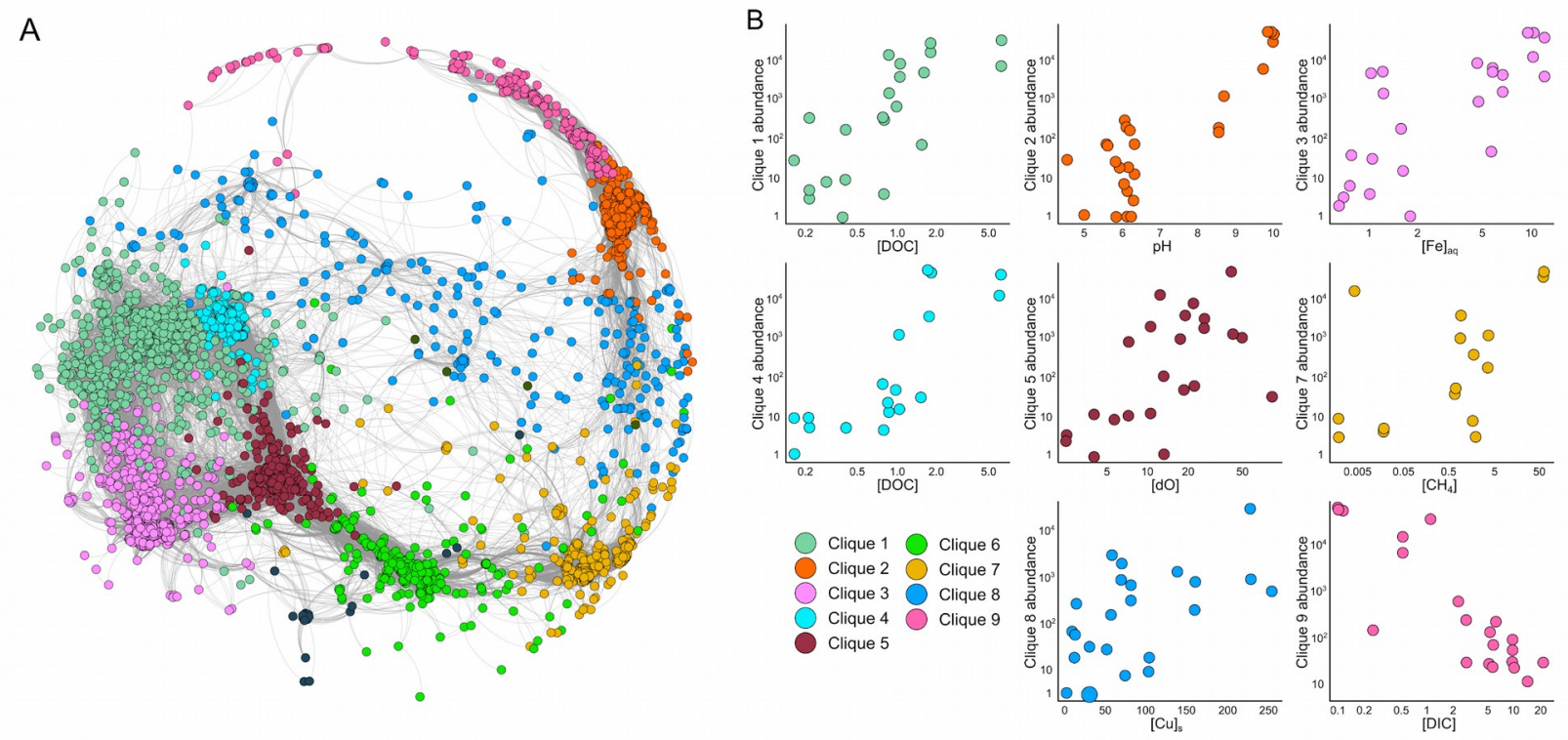

Figure 3. Bacterial cliques each have different relationships to subduction zone geochemistry. a) Co-occurrence network analysis of the dominant amplicon sequence variants (ASVs) across all sampling sites, colored by clique, with positive Spearman correlations $>0.65$ plotted as edges. b) Sum of ASVs in the cliques that were plotted against the subduction zone geochemical variables identified by Random Forest, Spearman correlation, and Pearson correlation, as the major explanatory variable for that clique. Cliques 6 and 10 were not significantly correlated with any geochemical variable. 

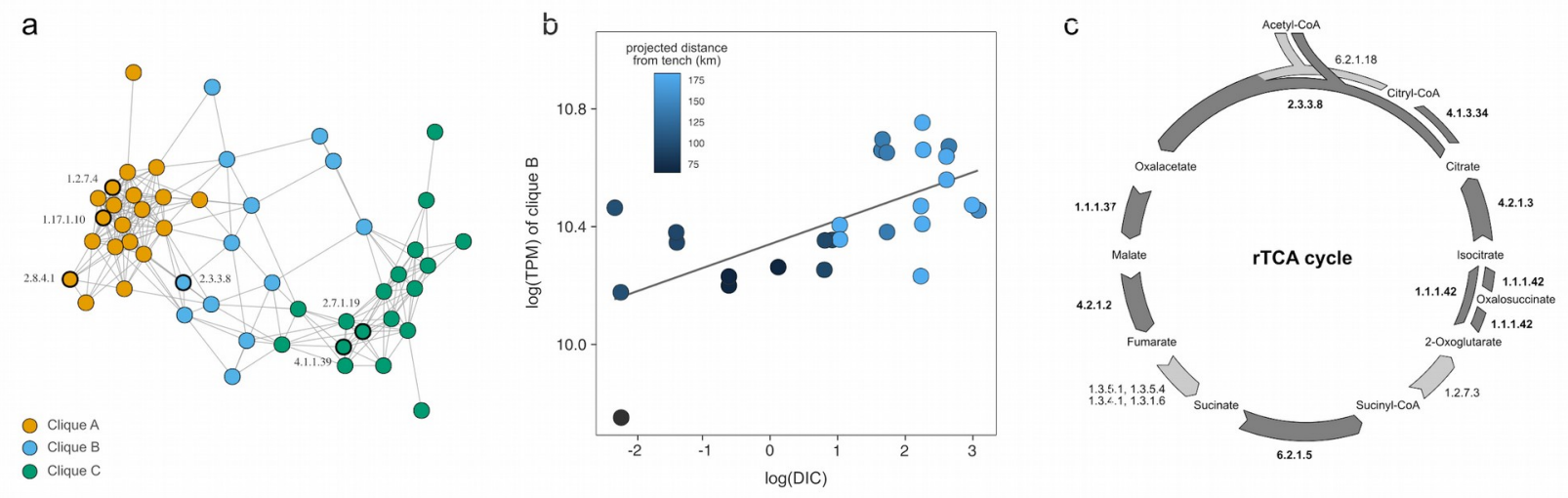

Figure 4. Metagenome-derived genes from the same carbon fixation pathway correlate with each other and with subduction zone geochemistry. a) Co-occurrence network analysis of the genes involved in all central carbon metabolism pathways with edges representing Spearman correlations with a $\rho>0.5(p<0.005)$. The key genes for the major carbon fixation pathways were recovered in discrete cliques: Wood-Ljungdahl (WL) key genes in clique A, reverse tricarboxylic acid (rTCA) genes in clique $\mathrm{B}$, and Calvin Benson Bassham (CBB) in clique C. The key genes for each pathway are highlighted with thicker outlines and have the EC number plotted. b) Sum of clique B genes plotted against DIC concentrations (in mmol C L ${ }^{-1}$ ) with blue color saturation corresponding to the distance from the trench (in $\mathrm{km}$ ) for each site (Spearman correlation of $\rho=0.66 \mathrm{p}<0.001$ ). c) diagram of the rTCA cycle with genes recovered in clique $\mathrm{B}$ highlighted in dark gray. These include the key genes ATP citrate (pro-S)-lyase and the citryl-CoA lyase necessary for the functioning of the two alternative versions of the rTCA cycle (Giovannelli et al. 2017). The two light gray rTCA genes were present in the samples but did not correlate as tightly with the other genes to be included in clique B, suggesting they were also used in other pathways. 


\section{Supplementary Discussion}

The network analysis examined only the most prevalent amplicon sequencing variants (ASVs), which accounted for $73 \%$ of the total reads, but only $12 \%$ of the total ASVs, so additional environmental interactions may occur among the rare organisms. ASVs with similar relative abundance patterns were divided into cliques based on their degree of connectivity in the network. The dominant environmental variable correlating with each clique was determined by combining Random Forest variable ranking results, with the top variable identified by correlative approaches (Pearson moment correlation and Spearman rank correlation coefficients, Tables S5S9).

Cliques 1 and 4 correlated positively with DOC concentrations (Fig. 3b). Clique 4 was dominated by Sulfurihydrogenibium (55\%), with $<10 \%$ contributions each from other members of the Hydrogenothermaceae, Hydrogenophilus, Meiothermus, and Rhodothermus. Cultured members of Sulfurihydrogenibium and Hydrogenothermaceae are facultative autotrophic sulfur and hydrogen oxidizers ${ }^{1}$ and members of the deep-branching phylum Aquificae ${ }^{2}$. Therefore, clique 4 may contain the main chemolithoautotrophs driving DOC production across the convergent margin transect. Clique 1 membership was much more evenly distributed, with $<10 \%$ contributions each from Chloroflexi, Firmicutes, Sulfurihydrogenibium, uncultured groups, and other organisms. Given the high diversity and prevalence of heterotrophic genera, members of clique 1 may be secondary consumers surviving on the organic carbon produced chemosynthetically by clique 4 . Members of clique 3 often co-occurred with members of cliques 1 and 4, suggesting that they too may contribute to the dominant chemosynthetic primary or secondary production, yet they correlated most closely with iron. The most abundant ASV in clique 3 was uncultured at the phylum level, so phylogeny-based functional inference was 
impossible, but clique 3 had $<10 \%$ contributions each from some of the same likely autotrophic and heterotrophic groups as cliques 1 and 4 , and environmental variable analysis suggest that iron may be an important cofactor for them.

Clique 2 correlated with $\mathrm{pH}$ and clique 9 correlated inversely with DIC (Fig. 3b). Clique 2 contained Hydrogenophilaceae and other facultatively autotrophic clades and clique 9 was 65\% Thiothrix with lesser proportions of Hydrogenophilaceae and Sulfuritalea, whose cultured members are chemolithoautotrophic sulfur oxidizers. The low DIC and high pH sites where these organisms were in highest relative abundance were the outer forearc sites (Figure S9), where the greatest extent of calcite sequestration was observed ${ }^{3}$. Therefore, these clades might have adaptations, such as high affinity for DIC, that allow them to sequester carbon even though the high $\mathrm{pH}$, low DIC, and low DOC suggest that they are DIC-limited ${ }^{3}$.

Clique 7 correlated with methane concentrations (Fig. 3b), however, only one genus, Methylocystis, contains cultured methanotrophs. Other members of clique 7 were likely heterotrophs (Chloroflexi, Prevotella, and Acidovorax), iron-cycling bacteria, or uncultured groups. Members of Clique 8 lacked tight co-occurrence patterns with each other (Fig. 4a), and contained a wide variety of cyanobacteria, nitrogen-cycling bacteria, heterotrophs, and uncultured clades. Clique 8 correlated positively with copper (Fig. 3b), and less significantly with cobalt, chromium, and cadmium, suggesting that these loose affiliations may be due to common metal demands for the members of clique 8 , rather than direct interactions between members or dependence on the same energy or carbon source.

Cliques 6 and 10 did not correlate with any environmental variables. Clique 10 was 94\% Sulfurihydrogenibium sp., and was found overly represented in the high temperature sites VC and TC. Clique 6 was 46\% Aquabacterium spp. and 22\% Alishewanella spp., which are common 
heat-tolerant bacteria from soils ${ }^{4}$ and freshwater ${ }^{5}$. Clique 6, therefore, served as an internal negative control, showing that when surface-associated bacteria were washed into the system, they did not correlate with deep subsurface geological parameters. Clique 5 may also be a surface-associated group, since it is $96 \%$ Tepidimonas sp., an obligate aerobe ${ }^{6}$ (54), and is correlated with dissolved oxygen.

\section{References for Supplemental Discussion}

1. Hayashi, N. R., Ishida, T., Yokota, A., Kodama, T. \& Igarashi, Y. Hydrogenophilus thermoluteolus gen. nov., sp. nov., a thermophilic, facultatively chemolithoautotrophic, hydrogen-oxidizing bacterium. Int. J. Syst. Evol. Microbiol. 49, 783-786 (1999).

2. Giovannelli, D. et al. Insight into the evolution of microbial metabolism from the deepbranching bacterium, Thermovibrio ammonificans. eLife 6, (2017).

3. Barry, P. H. et al. Forearc carbon sink reduces long-term volatile recycling into the mantle. Nature 568, 487-492 (2019).

4. Kim, M.-S., Jo, S. K., Roh, S. W. \& Bae, J.-W. Alishewanella agri sp. nov., isolated from landfill soil. Int. J. Syst. Evol. Microbiol. 60, 2199-2203 (2010).

5. Chen, W.-M. et al. Aquabacterium limnoticum sp. nov., isolated from a freshwater spring. Int. J. Syst. Evol. Microbiol. 62, 698-704 (2012).

6. Albuquerque, L., Tiago, I., Verissimo, A. \& da Costa, M. S. Tepidimonas thermarum sp. nov., a new slightly thermophilic betaproteobacterium isolated from the Elisenquelle in Aachen and emended description of the genus Tepidimonas. Syst. Appl. Microbiol. 29, 450-456 (2006). 


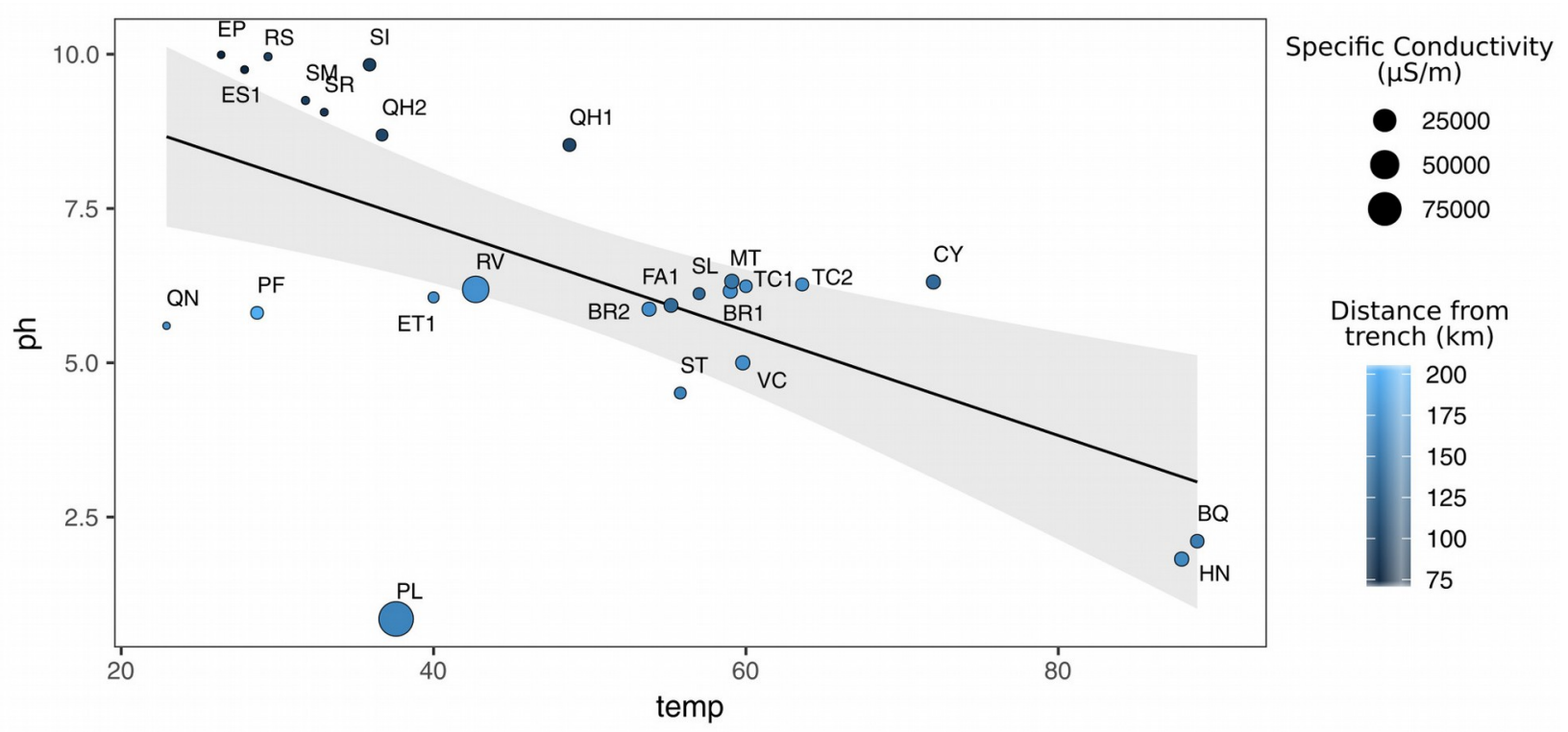

Fig. S1. Plot showing the relationship between temperature, $\mathrm{pH}$, specific conductivity and distance from trench for the sampled hot springs. The Pearson correlation between temperature and $\mathrm{pH}$ measurements carried out in the field is -0.602. Poás acid Lake (PL) sample falls significantly below the trend line. The measured temperature of PL waters was influenced by the low activity of the magmatic-hydrothermal system underlying the crater lake during the sampling days in late February 2017. The volcanic activity increased in early April 2017 culminating with renewal of phreatomagmatic eruptions completely evaporating the acid crater lake. 


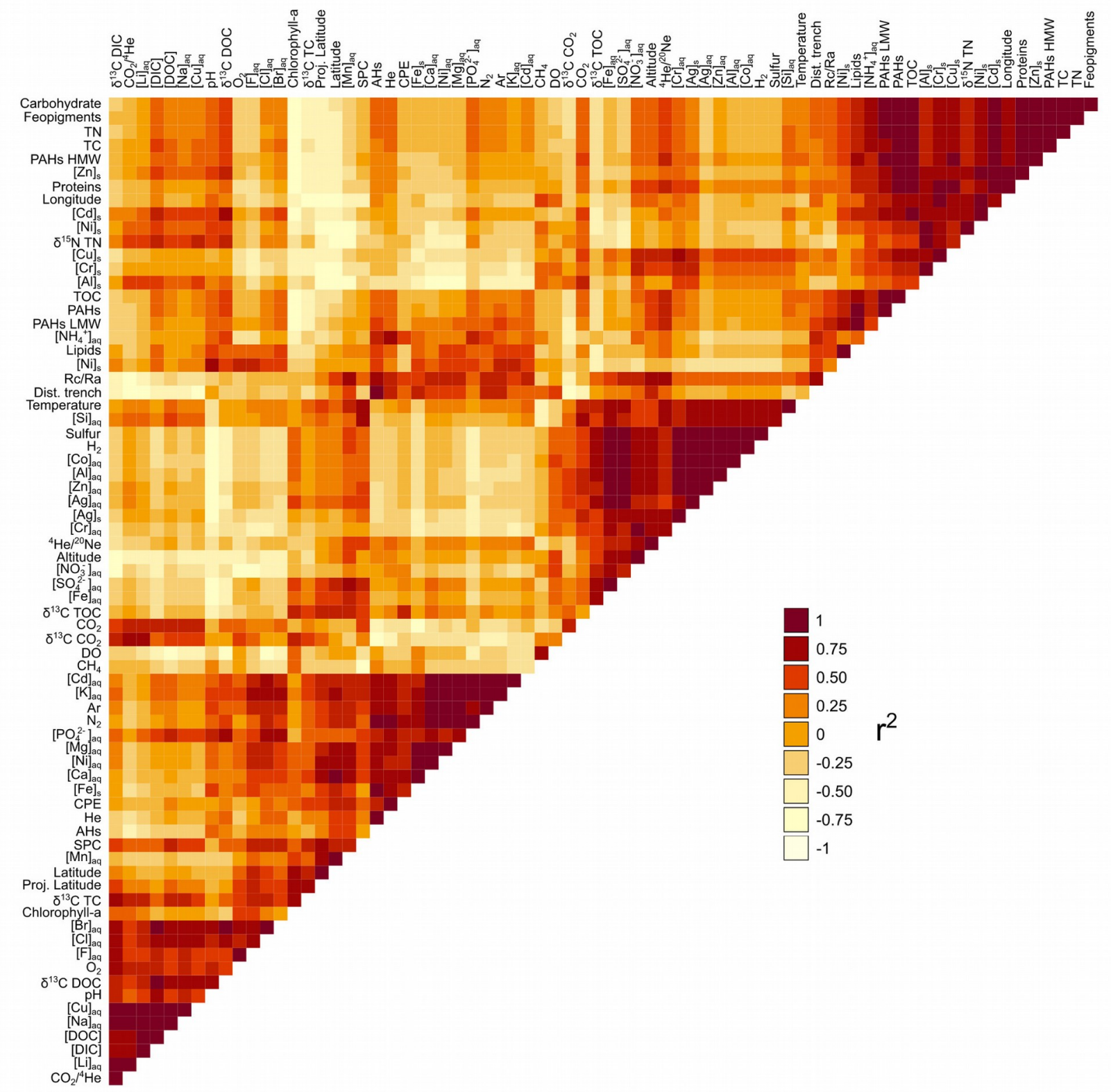

Fig. S2. Matrix of correlation (Pearson moment correlation) among the environmental and geochemical variables showing strong covariance among some of the investigated parameters. 


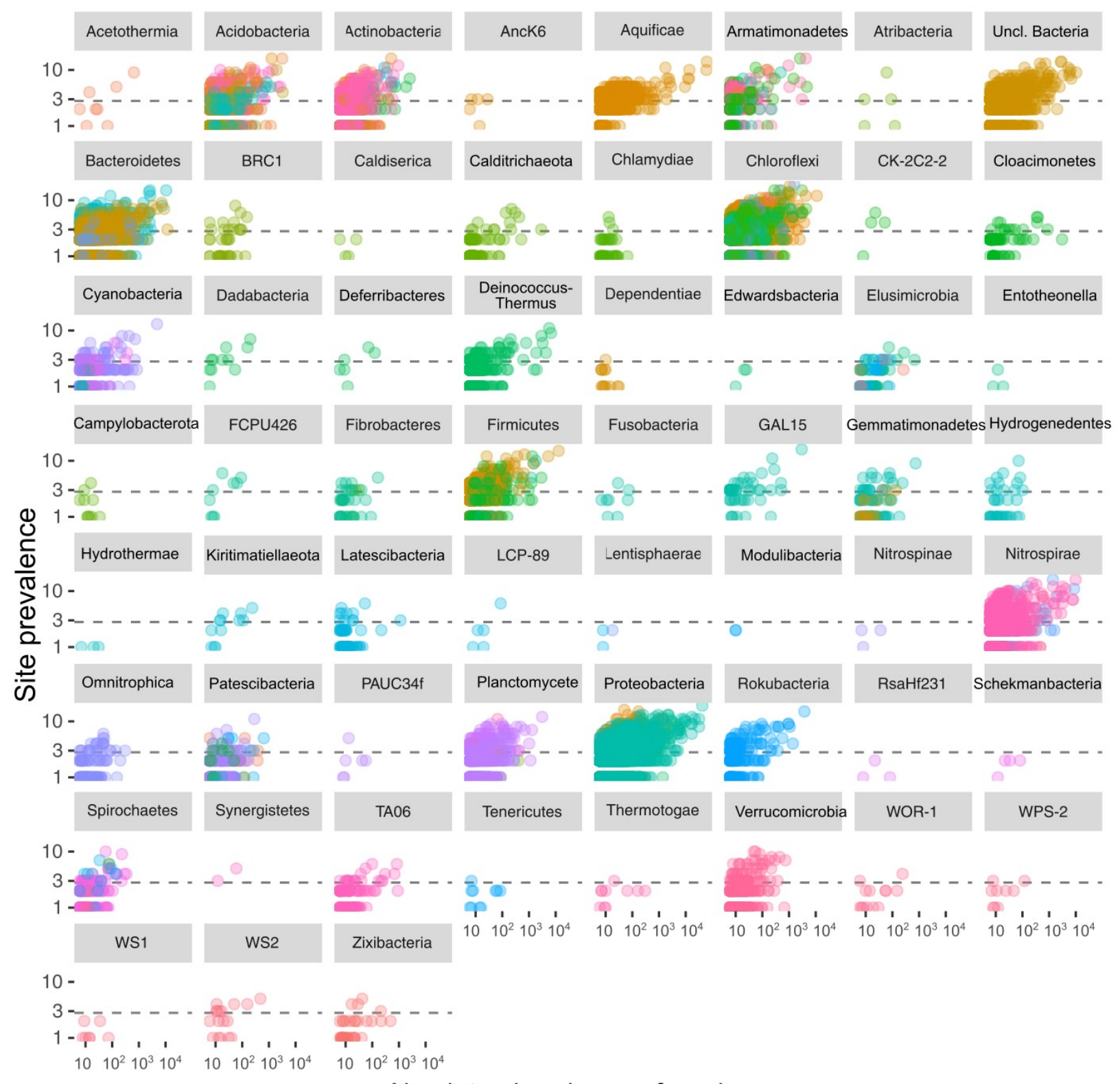

Absolute abundance of reads

Fig. S3. Prevalence analysis of the 16S rRNA gene amplicon bacterial community across the investigated samples. Amplicon Sequencing Variants (ASV) with an abundance of normalized reads below 5 and presence in less than 3 sites were removed from analyses. The multiple colors within each panel represent different families for that phylum. 
Fig. S4. Figure_prevalence_filtering. Comparison of the broad phylum level classification of each site diversity before (A) and after (B) prevalence filtering preceding the co-occurrence network analysis. ASV with less than 5 reads and not appearing at least in 3 samples were removed. Poás Lake (PL) was removed from the analysis before prevalence filtering since it is not a hot spring. The diversity patterns remain the same. Before filtering: 33,187 ASVs in 
1,854,259 reads; After prevalence filtering for the co-occurrence network 3,935 ASVs in $1,299,144$ reads. In total $70.1 \%$ of the reads were retained after prevalence filtering representing $11.9 \%$ of the ASVs.

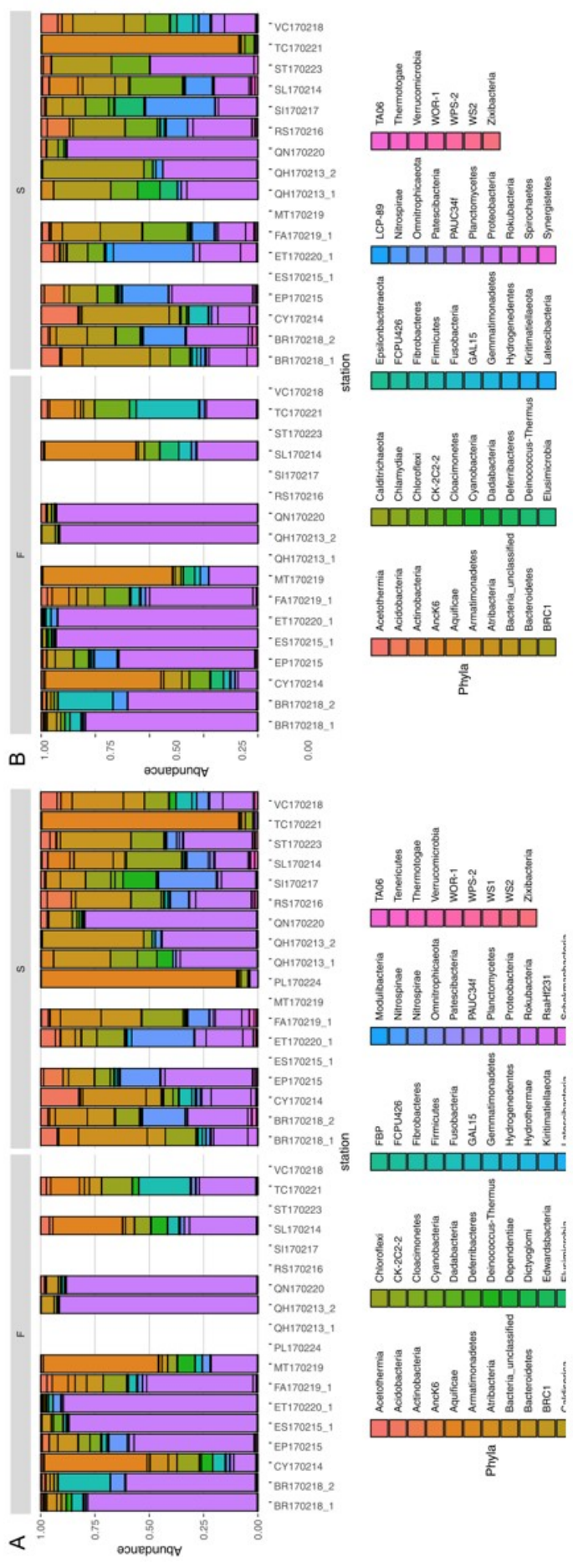



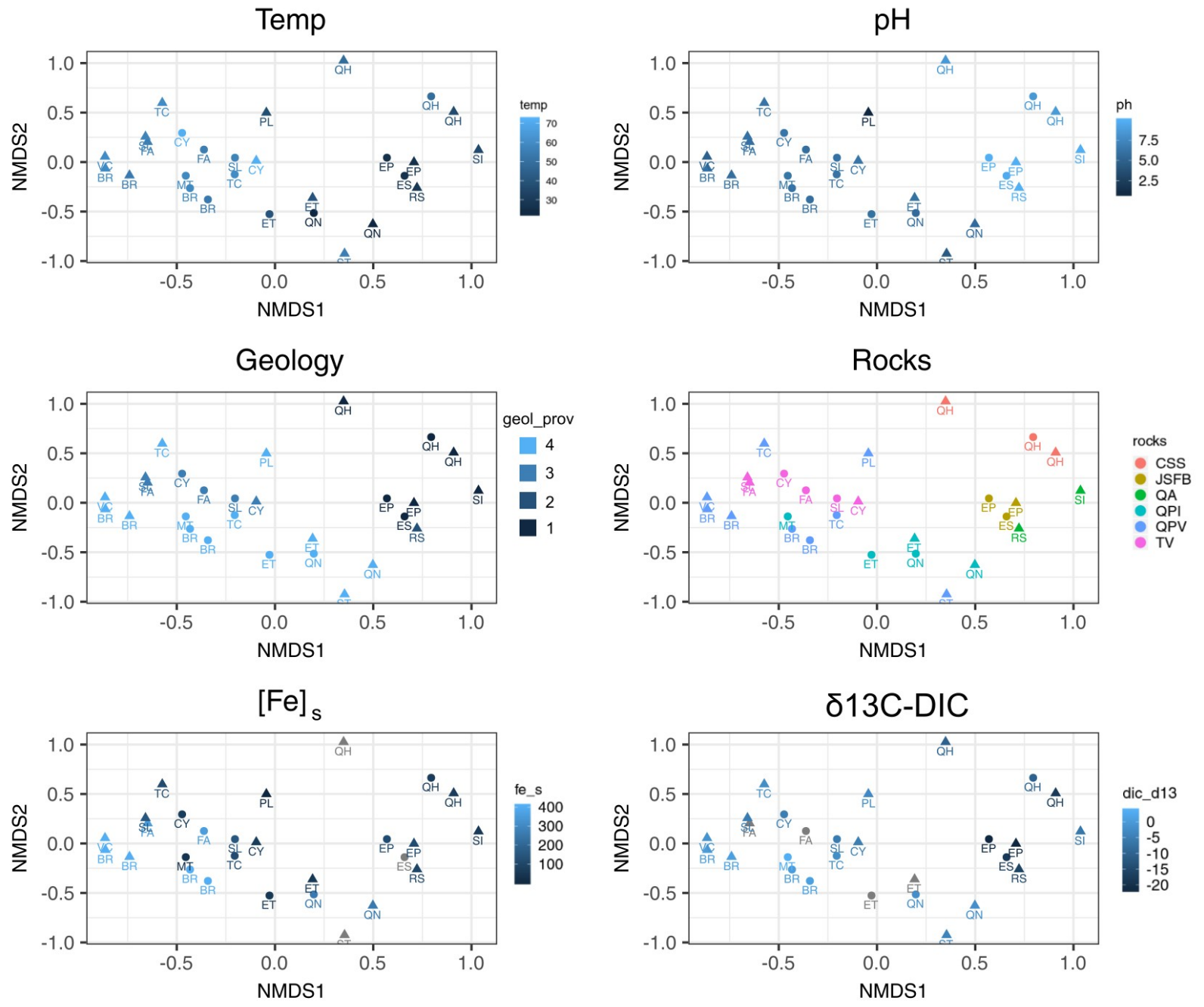

Fig. S5. nMDS plots based on the Bray-Curtis similarity index colored by different environmental variables. Circles represent fluid samples and triangles sediment samples. Temperature, $\mathrm{pH}$, geological province, basement rock types, and concentrations of $\left[\mathrm{Fe}_{s}\right]$ and [DIC]. 


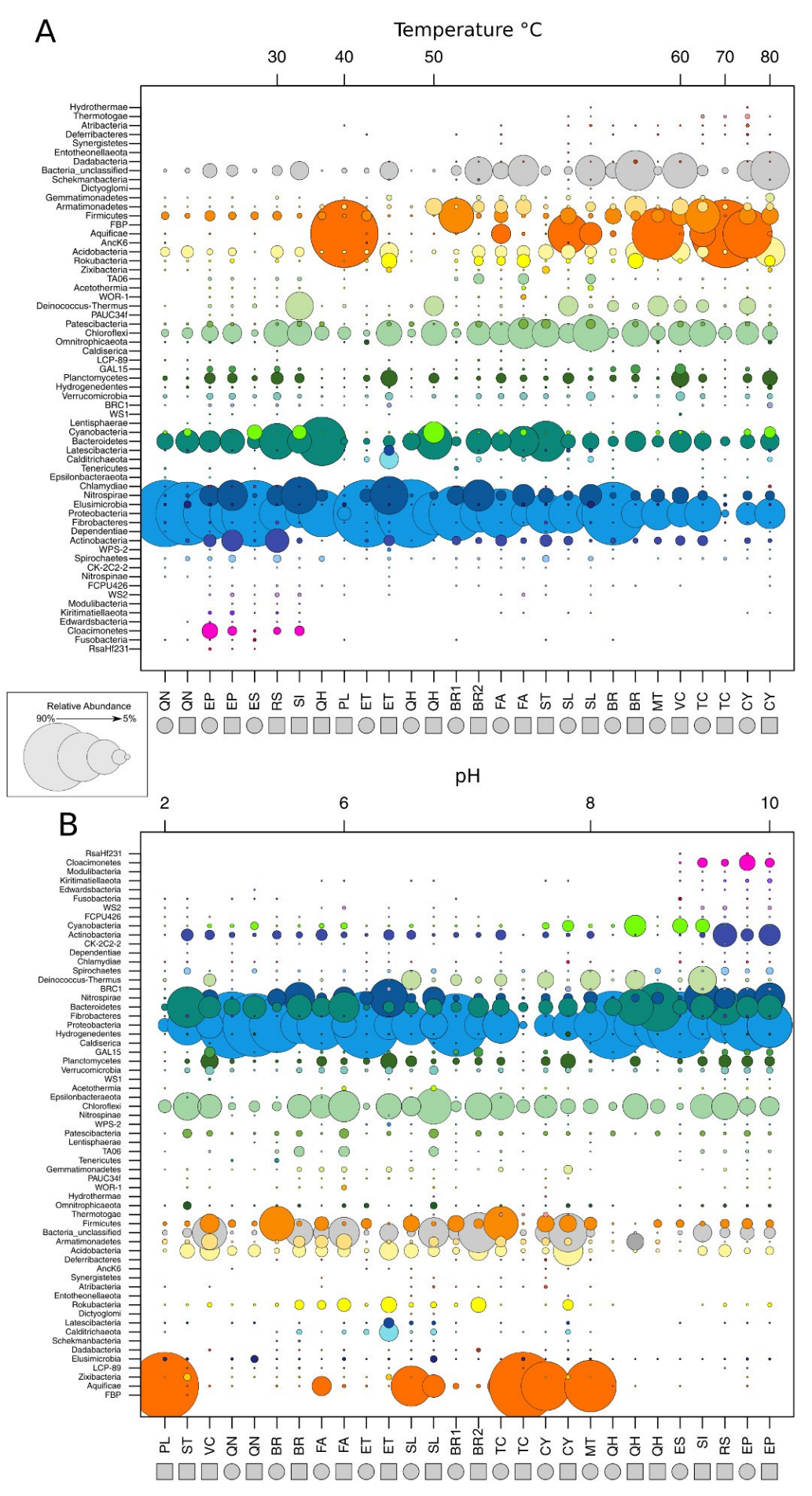

Fig. S6. Plot of the relative abundance of the identified bacterial phyla in the sample stations ordered by site temperature (A) and $\mathrm{pH}(\mathrm{B})$, respectively. The size of the colored circles is proportional to the relative abundance of the taxa, gray squares are sediments and gray circles are fluids and vertical ordering is by the strength of correlation with temperature (A) and $\mathrm{pH}(\mathrm{B})$. 

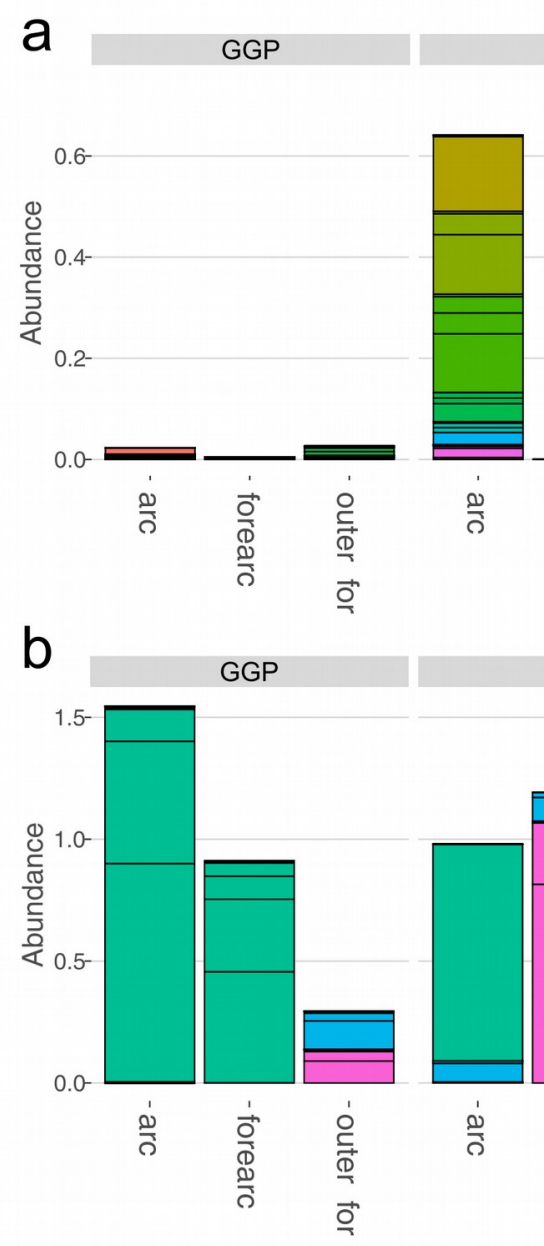

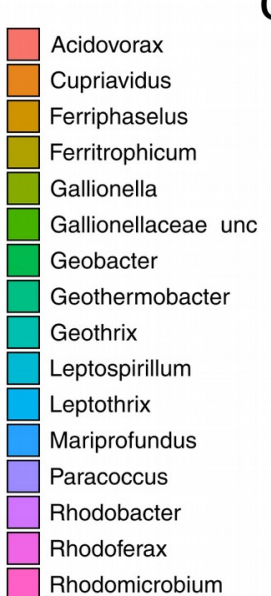

Rhodomicrobium

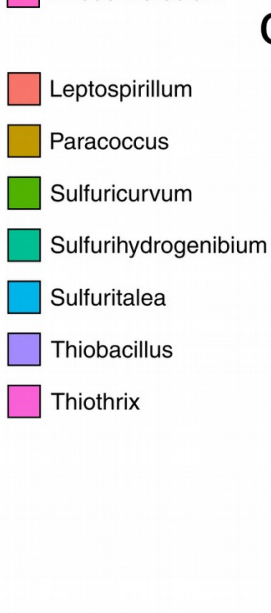

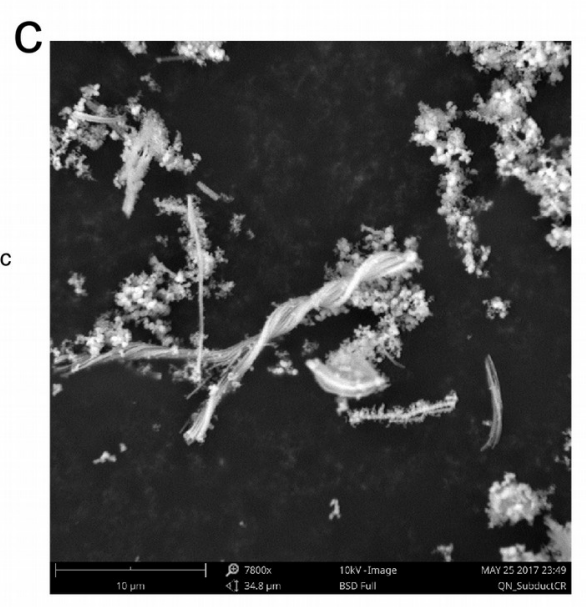

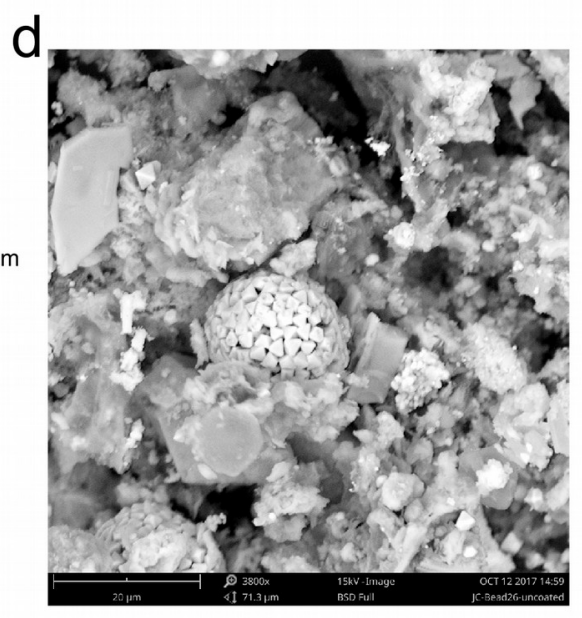

Fig. S7. Bacterial sulfur oxidation occurs throughout the forearc/arc, whereas iron oxidation occurs only in the Central Cordillera. Relative cumulative abundance of putative iron (a) and sulfur (b) oxidizing genera across the sites corresponding to the two subducting plates. Sites are grouped according to the arc province (arc, forearc, outer forearc) and the two arc regions: the Guanacaste Geological Province (GGP) associated with the East Pacific Rise in north Costa Rica and the Central Cordillera (CC) associated with the Nazca-Cocos Spreading center in central Costa Rica. Note the difference in abundance scales (\%) between the two plots. Lines drawn within a single box color represent contributions from different samples. Scanning electron micrographs show pyrite framboids at SL (d) and twisted stalks of iron hydroxides deposited by iron-oxidizing bacteria at QN (c). 


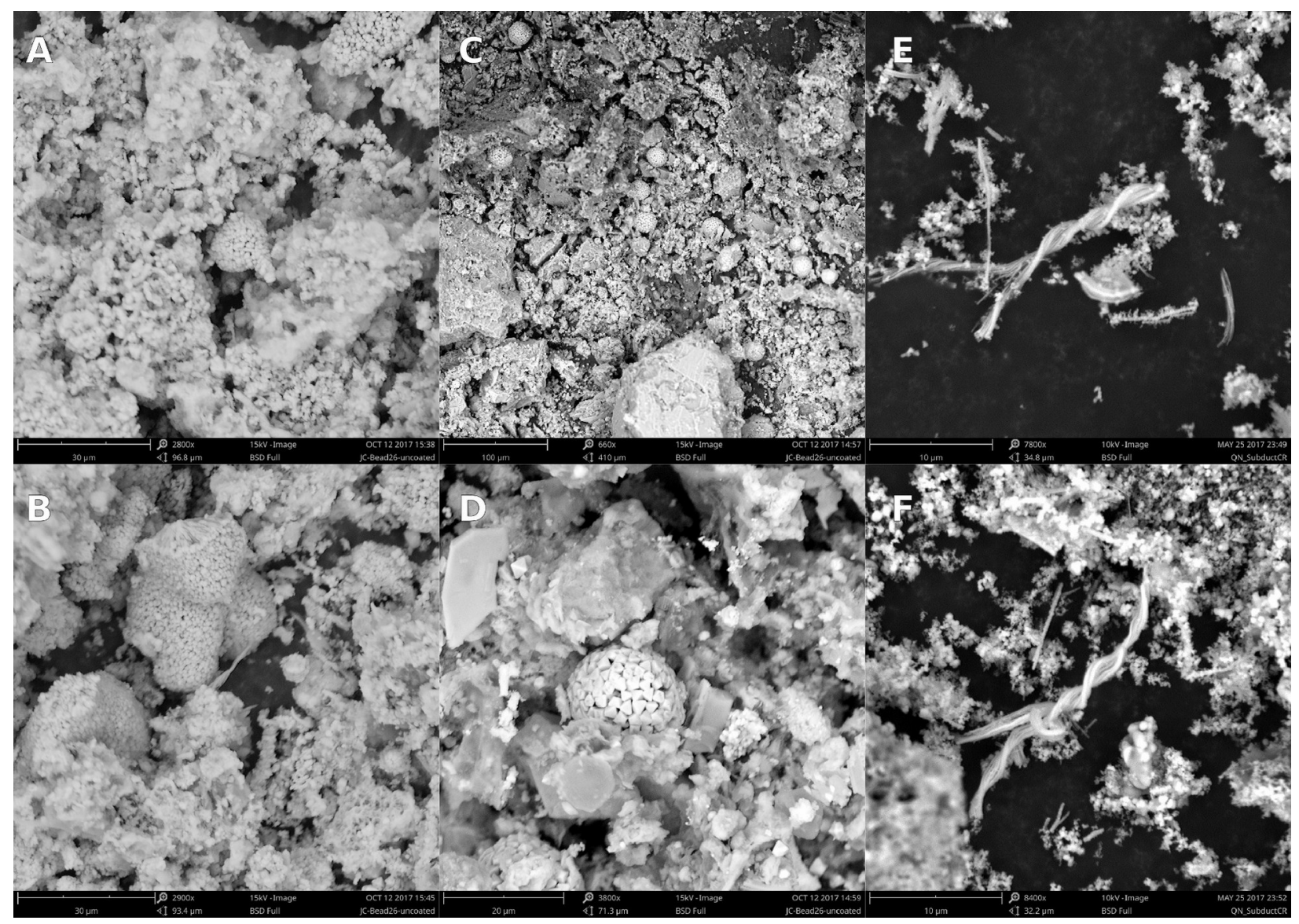

Fig. S8. Scanning electron microscope micrographs representative of the mineral morphologies identified in the sediments of selected hot springs. A, B - Blue River (BR) site; C, D - Santa Lucía (SL) site, pyrite framboids are clearly visible in this samples suggesting iron sulfide precipitations; E, F - Quebrada Naranja (QN) site, iron hydroxide twisted stalks are clearly visible in the sample suggesting active microbial iron oxidation. Mineralogy was determined via Energy Dispersive X-Ray Spectroscopy (EDX) and X-Ray Diffraction (XRD). 


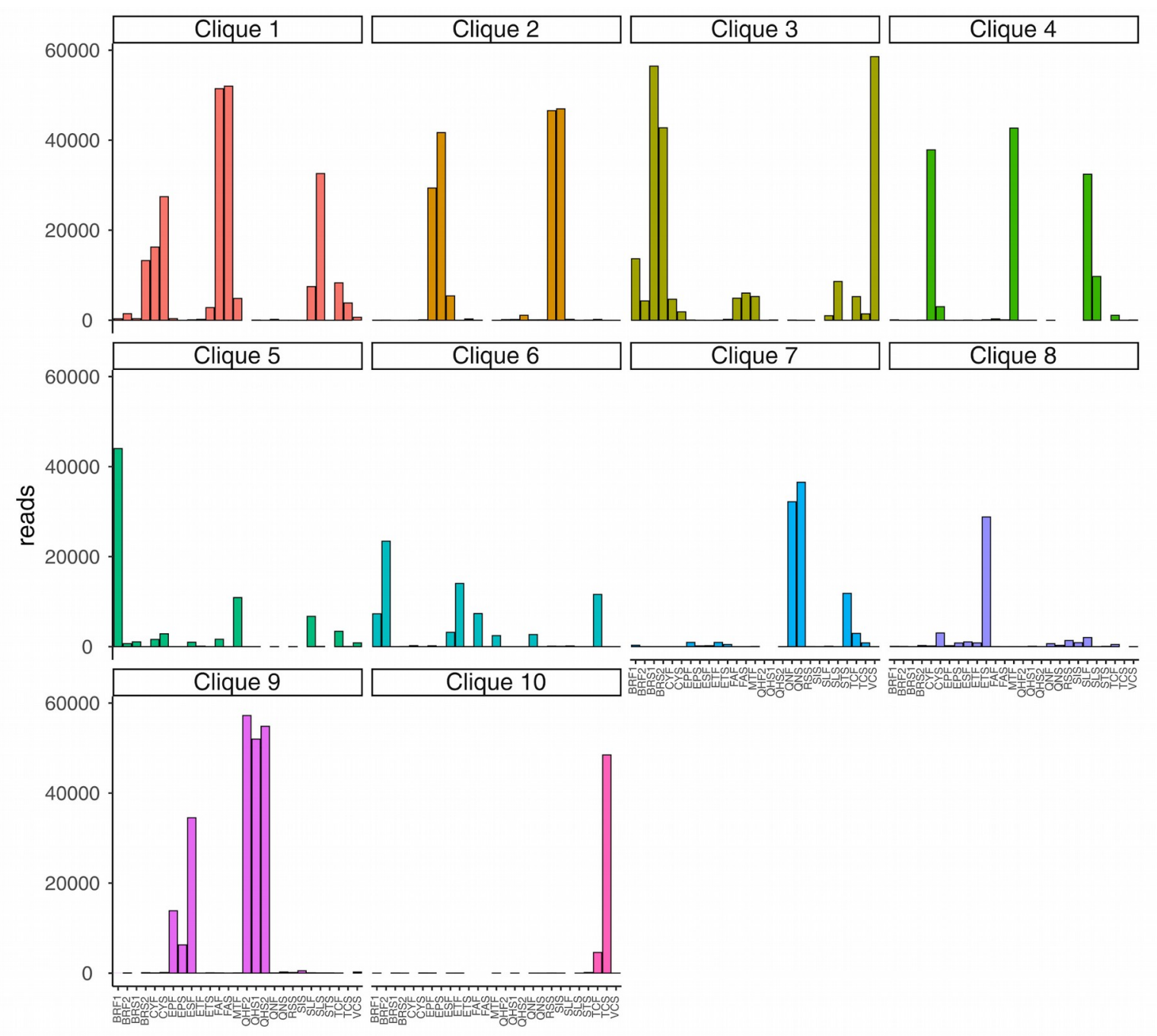

Fig. S9. Read distribution of each clique across all samples. 


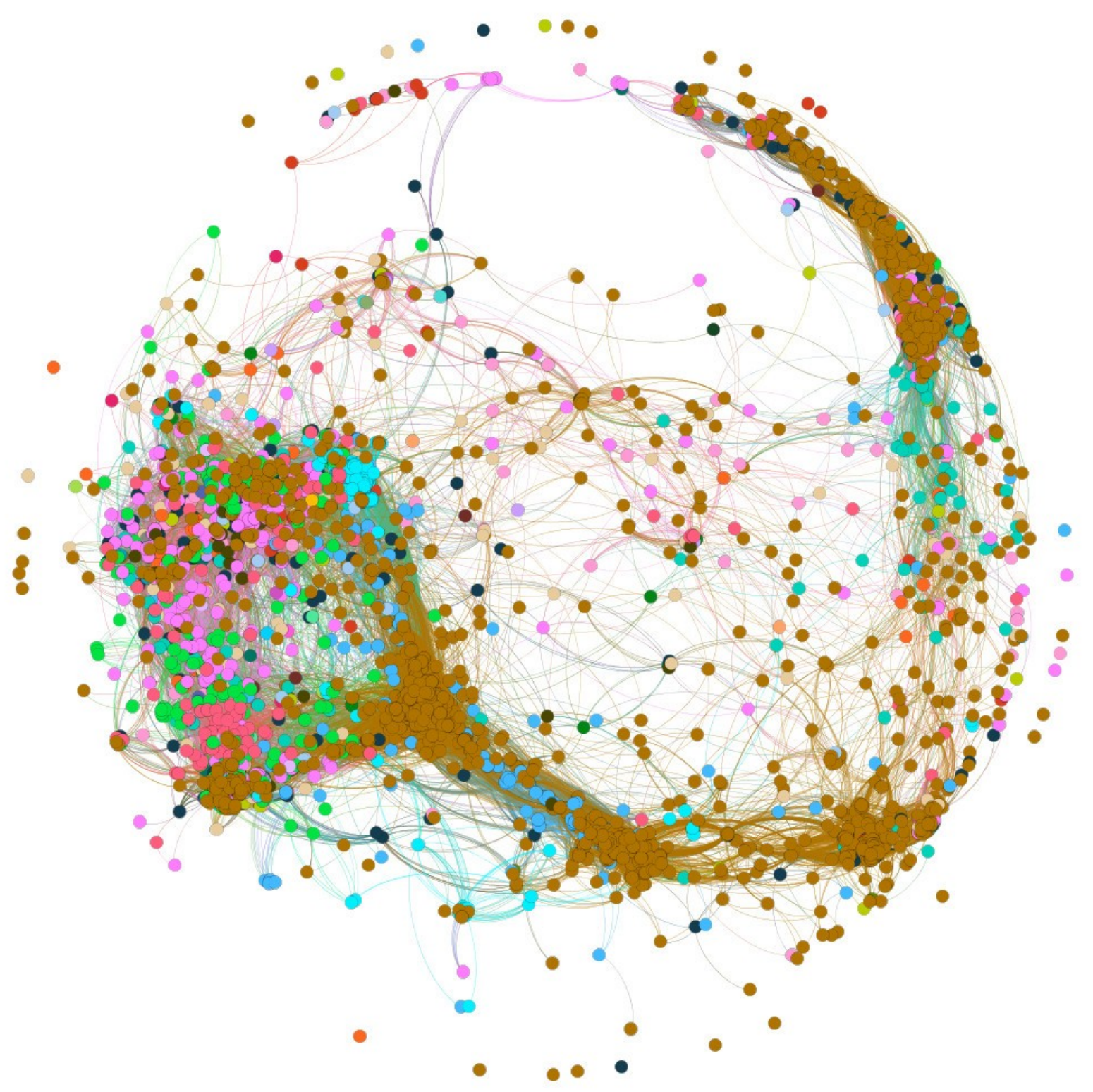

Fig. S10. Co-occurrence network of the dominant ASVs in the fluids and sediments presented in Figure 3 colored by phyla. ASVs are represented by a vertex, edges represent pairwise Spearman correlations above 0.65 . 


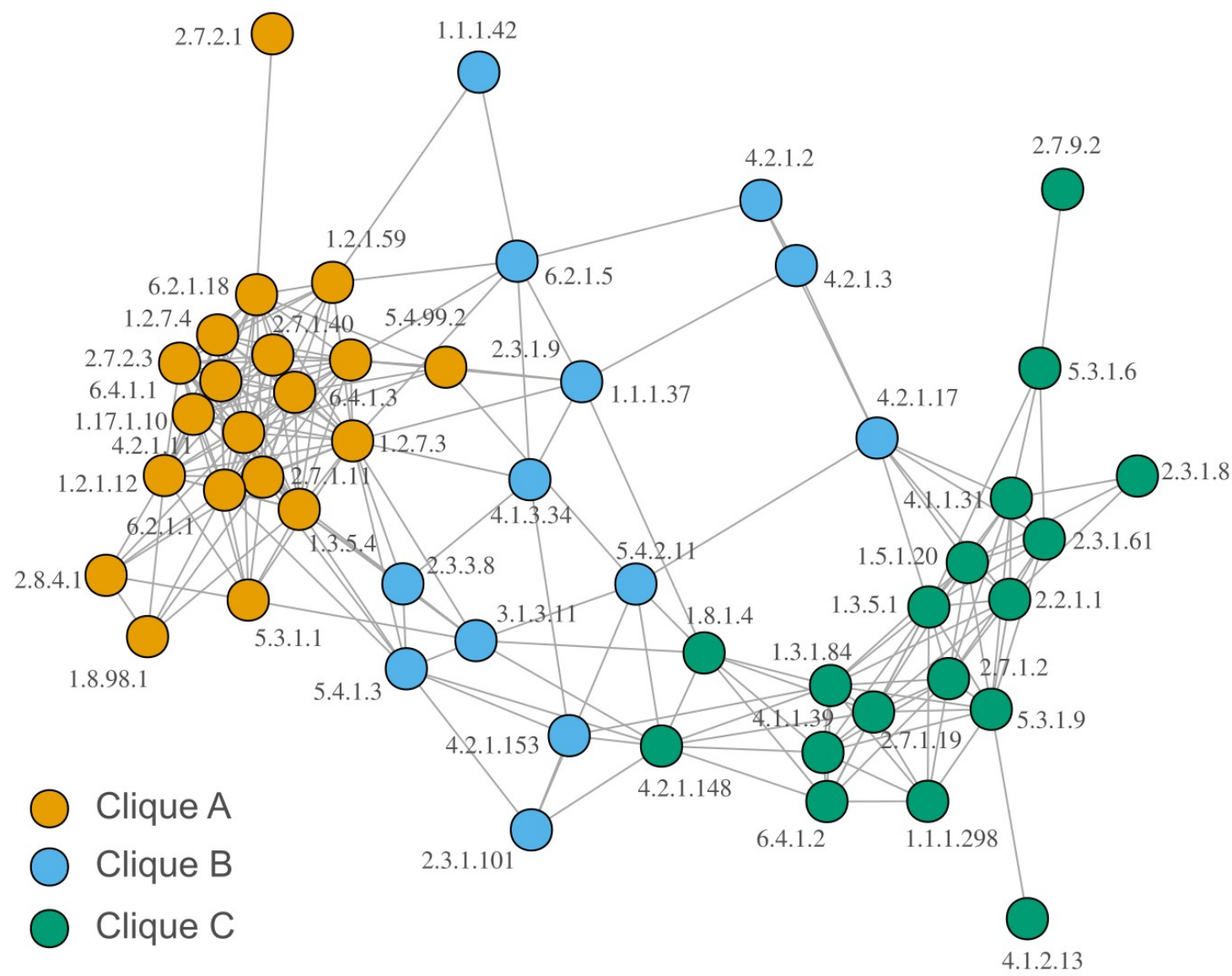

Fig. S11. Co-occurrence network analysis of the carbon genes involved in the major carbon fixation and carbon metabolism pathways. This plot is the same as Fig. 4a, but with all the EC numbers shown. The key genes are highlighted according to their clique assignment based on a greedy clustering algorithm. EC numbers assignments are plotted for each vertex. Only Spearman correlations with a $p>0.5(p<0.005)$ are plotted as edges in the network. 

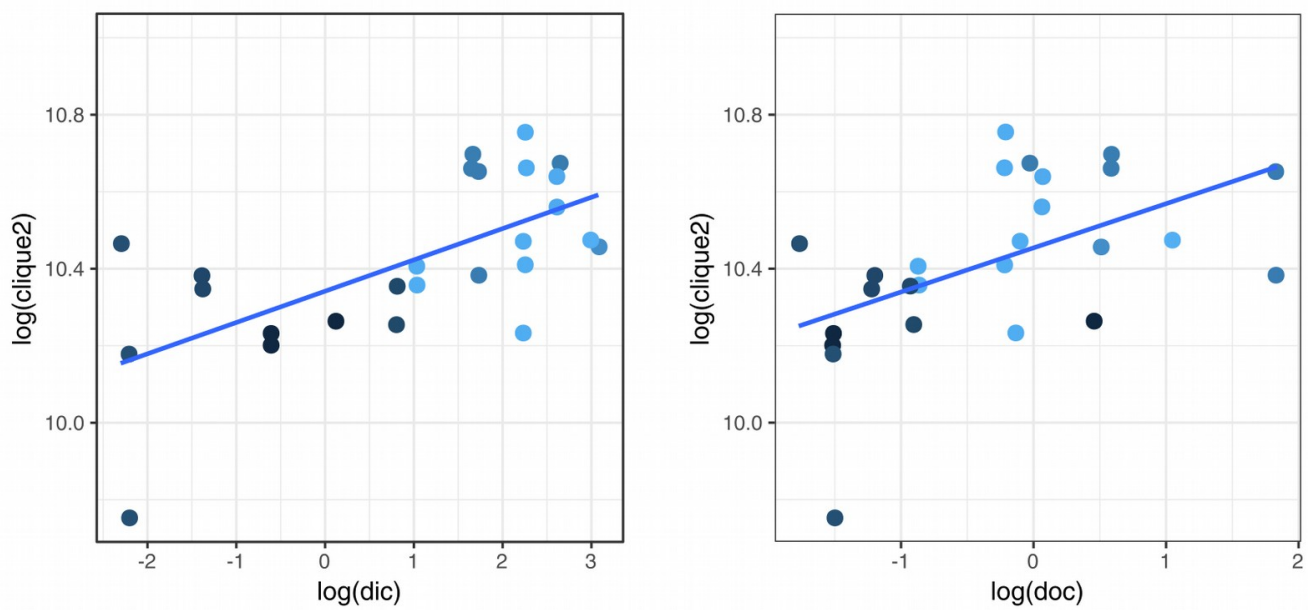

projected distance from trench $(\mathrm{km})$
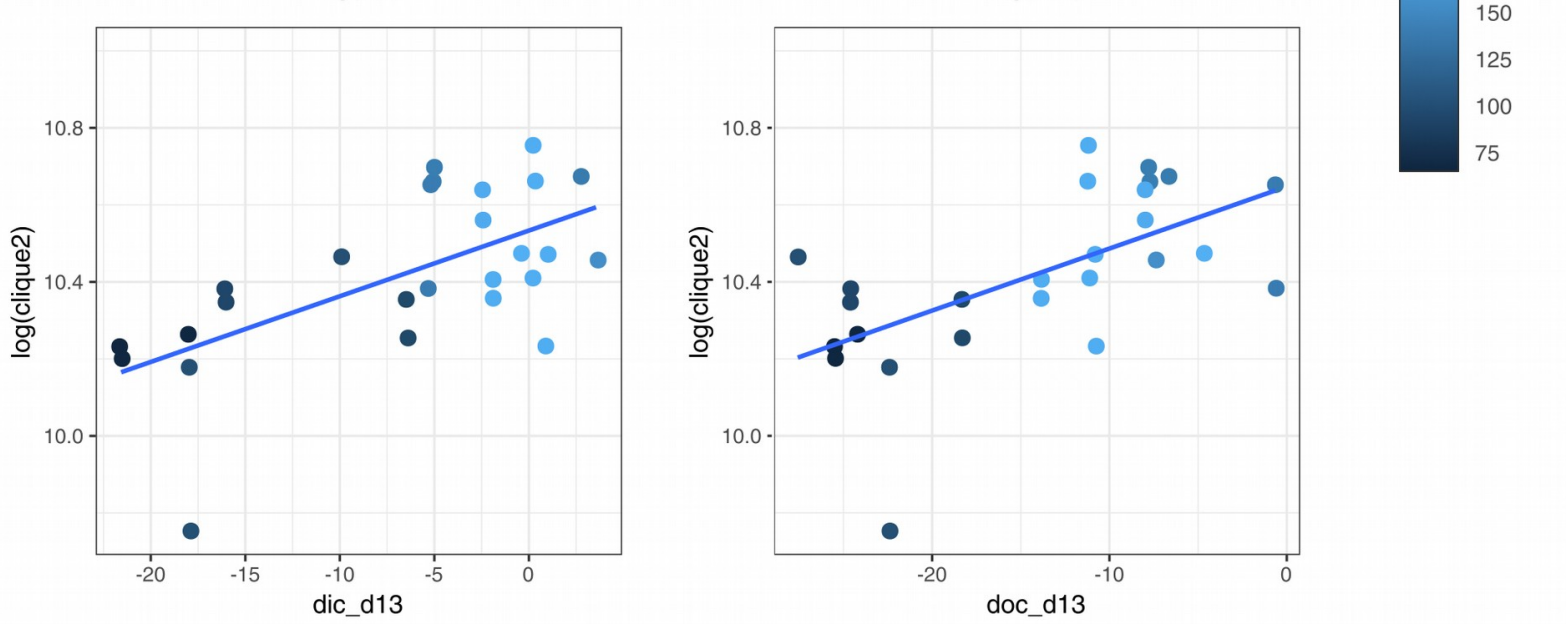

Fig. S12. Correlations of clique B with DIC and DOC concentrations and their $\delta^{13} \mathrm{C}$ isotopic signatures overprinted with the projected distance from the trench (in $\mathrm{km}$ ) for each site. Spearman correlations for each relationship are: DIC $\rho=0.66 \mathrm{p}<0.001$, DOC $\rho=0.60 \mathrm{p}<0.01, \delta^{13} \mathrm{C}$ DIC $\rho=0.62 \mathrm{p}<0.001, \delta^{13} \mathrm{C}$-DOC $\rho=0.64 \mathrm{p}<0.001$, respectively. 